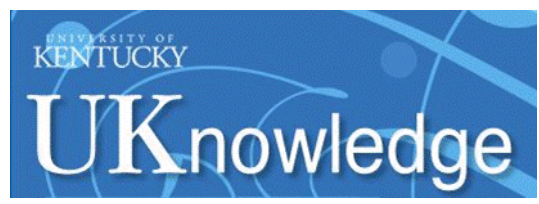

University of Kentucky

UKnowledge

\title{
Student Perceived Motivational Climate, Enjoyment, and Physical Activity in Middle School Physical Education
}

Christine Elizabeth Johnson

University of Kentucky, johnsonc@westga.edu

Right click to open a feedback form in a new tab to let us know how this document benefits you.

\section{Recommended Citation}

Johnson, Christine Elizabeth, "Student Perceived Motivational Climate, Enjoyment, and Physical Activity in Middle School Physical Education" (2015). Theses and Dissertations--Education Sciences. 6.

https://uknowledge.uky.edu/edsc_etds/6

This Doctoral Dissertation is brought to you for free and open access by the College of Education at UKnowledge. It has been accepted for inclusion in Theses and Dissertations--Education Sciences by an authorized administrator of UKnowledge. For more information, please contact UKnowledge@lsv.uky.edu. 


\section{STUDENT AGREEMENT:}

I represent that my thesis or dissertation and abstract are my original work. Proper attribution has been given to all outside sources. I understand that I am solely responsible for obtaining any needed copyright permissions. I have obtained needed written permission statement(s) from the owner(s) of each third-party copyrighted matter to be included in my work, allowing electronic distribution (if such use is not permitted by the fair use doctrine) which will be submitted to UKnowledge as Additional File.

I hereby grant to The University of Kentucky and its agents the irrevocable, non-exclusive, and royalty-free license to archive and make accessible my work in whole or in part in all forms of media, now or hereafter known. I agree that the document mentioned above may be made available immediately for worldwide access unless an embargo applies.

I retain all other ownership rights to the copyright of my work. I also retain the right to use in future works (such as articles or books) all or part of my work. I understand that I am free to register the copyright to my work.

\section{REVIEW, APPROVAL AND ACCEPTANCE}

The document mentioned above has been reviewed and accepted by the student's advisor, on behalf of the advisory committee, and by the Director of Graduate Studies (DGS), on behalf of the program; we verify that this is the final, approved version of the student's thesis including all changes required by the advisory committee. The undersigned agree to abide by the statements above.

Christine Elizabeth Johnson, Student

Dr. Heather Erwin, Major Professor

Dr. Robert Shapiro, Director of Graduate Studies 
STUDENT PERCEIVED MOTIVATIONAL CLIMATE, ENJOYMENT, AND PHYSICAL ACTIVITY IN MIDDLE SCHOOL PHYSICAL EDUCATION

\title{
DISSERTATION
}

A dissertation submitted in partial fulfillment of the requirements for the degree of Doctor of Philosophy in the College of Education at the University of Kentucky

\author{
By \\ Christine Elizabeth Johnson \\ Lexington, Kentucky
}

Director: Dr. Heather Erwin, Associate Professor of Kinesiology and Health Promotion, Director of Graduate Studies

Lexington, Kentucky

2015

Copyright (C) Christine Elizabeth Johnson 2015 


\section{ABSTRACT OF DISSERTATION}

\section{STUDENT PERCEIVED MOTIVATIONAL CLIMATE, ENJOYMENT, AND PHYSICAL ACTIVITY IN MIDDLE SCHOOL PHYSICAL EDUCATION}

Youth physical activity (PA) levels, specifically that of girls, decline as they enter the middle grades (Parish \& Treasure, 2003). Physical education (PE) is one area in the school environment where student PA can be increased. One goal recognized by the Society of Health and Physical Educators (SHAPE) is for students to be physically active for at least $50 \%$ of class time and be offered PE for at least 225 minutes per week (SHAPE, 2013). Achievement Goal Theory (AGT) suggests student perceived motivational climate can influence PA levels, student enjoyment, and intrinsic motivation. The purpose of this study was to determine if student perceived motivational climate predicted student enjoyment and PA levels in PE while controlling for school, gender, grade, and ethnicity. Youth from three middle schools in the southeast United States were asked to wear a pedometer to measure PA levels in PE and complete a questionnaire to measure perceived motivational climate and enjoyment. Participants included 290 students $\left(n=1086^{\text {th }}\right.$ grade students, $n=947^{\text {th }}$ grade students, $n=888^{\text {th }}$ grade students). Results revealed males were more active than females during PE $\left(\mathrm{M}_{\mathrm{m}}=57 \%, \mathrm{M}_{\mathrm{f}}=48 \%\right), 7^{\text {th }}$ grade participants had the highest PA levels ( $\left.\mathrm{M}=56 \%, \mathrm{SD}=16\right)$, and Hispanic students were the least active $(\mathrm{M}=45 \%, \mathrm{SD}=16)$. After controlling for gender, it was found that males had significantly higher levels of enjoyment during $\mathrm{PE}$ $\left(\mathrm{M}_{\mathrm{m}}=4.29, \mathrm{M}_{\mathrm{f}}=3.87, \mathrm{p}<.01\right)$, and a mastery climate was perceived over a performance climate by majority of student regardless of gender, grade, or ethnicity $\left(\mathrm{M}_{\mathrm{mc}}=3.78\right.$, $\mathrm{M}_{\mathrm{pc}}=2.2$ ). Statistically significant relationships were found between both mastery $(\mathrm{p}<.01)$ and performance scores $(\mathrm{p}<.01)$ with enjoyment. The performance relationship was negative while the mastery relationship was positive. There was not a significant relationship between the mastery climate and PA and only the performance climate subcategory Unequal Recognition $(\mathrm{p}<.001)$ had a significant relationship with and PA during PE.

KEYWORDS: Physical Education, PMCSQ-2, PACES 
_Christine Johnson

Student's Signature

December 15, 2015

Date 
STUDENT PERCEIVED MOTIVATIONAL CLIMATE, ENJOYMENT, AND PHYSICAL ACTIVITY IN MIDDLE SCHOOL PHYSICAL EDUCATION

\section{By}

Christine Elizabeth Johnson

Dr. Heather Erwin

Director of Dissertation

Dr. Robert Shapiro

Director of Graduate Studies

December 15, 2015

Date 
For my family - Scott, Beckie, Sarah, Kelsey, Chandler, and Alison 


\section{ACKNOWLEDGMENTS}

The completion of my dissertation could not have been possible without guidance and support from my committee members and family.

First, I would like to thank Dr. Heather Erwin. She provided me with constant feedback and support throughout this program. She went above and beyond what was required of her to help me fully understand and navigate this entire process. I am so grateful for her support and encouragement. I would also like to thank Dr. Aaron Beighle. He has helped guide me while finding my 'nitch.' His perspectives both challenged and encouraged me throughout this program. Additionally, I would like to thank Dr. Lindsay Kipp. She was an excellent mentor not only while helping me through the data analysis section, but any another other question I had throughout this dissertation. Dr. Sharon Brennan discussed the importance of the learning environment with me multiple times in this program. She was a great source of knowledge, and I am very thankful for her input and enthusiasm for this dissertation. Dr. Melinda Ickes asked tough questions that guided me to make this dissertation not only possible, but the best version it could be. Her feedback was critical in assisting me throughout the dissertation process. It was an incredible experience to work with such well respected individuals in the Department of Kinesiology and Health Promotion, and I am so thankful to have had this opportunity.

The completion of this dissertation would not have been possible without the support and guidance from my family and God. My family has been so strong throughout the past three years, and I am so blessed to be able to make them proud. When I was stressed and had doubts, they were there to continue pushing me in this journey. They were also there to share all of the milestone moments. I am forever grateful to my Mom, 
Dad, and sisters, Sarah and Kelsey. This program has strengthened all of my relationships with my family and God in ways I could not have imagined.

Finally, I would like to thank the University of Kentucky and the Department of Kinesiology and Health Promotion. It was an amazing experience that will stay with me for the rest of my life. 


\section{TABLE OF CONTENTS}

Acknowledgments..........................................................ii



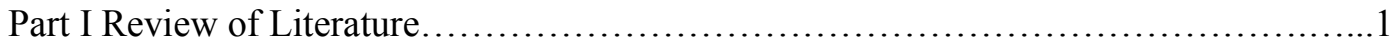

Physical Activity Out of School..........................................

Physical Activity Before and After School...................................2

Family and Community Engagement.......................................

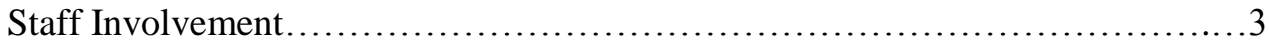

Physical Activity in School.............................................

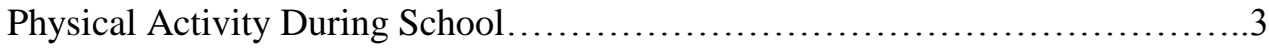

Physical Education in School.............................................4

Physical Activity in Physical Education....................................

Age and Physical Activity............................................... 9

Ethnicity and Physical Activity ........................................ 10

Gender and Physical Activity...........................................11

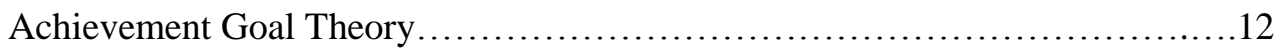

Ego- and Task-Involved Goals.........................................13

The Climate............................................................. 13

Performance Climate...................................................... 14

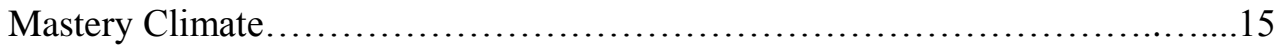

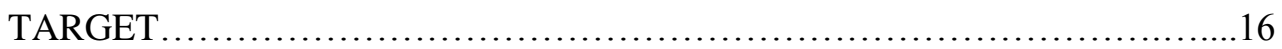

Motivational Climate Research..........................................17

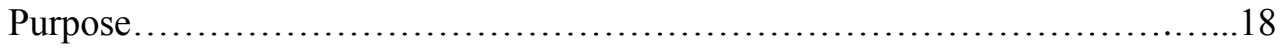

Hypotheses...................................................... 19

Part II Descriptive Analysis................................................ 21

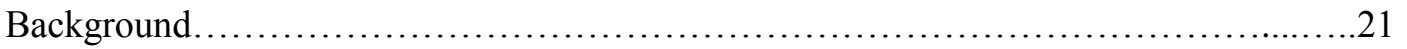

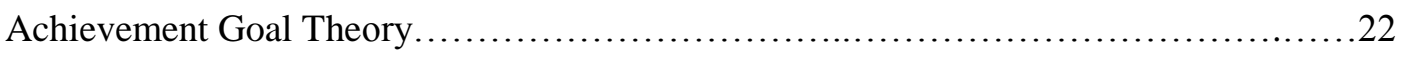

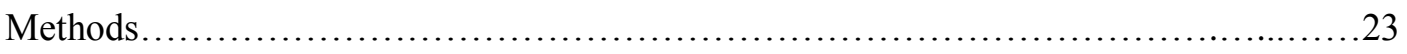

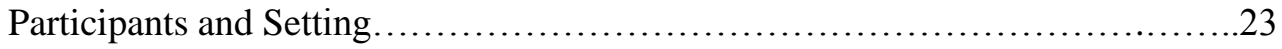

Measures/Instruments...............................................24

Perceptions of Motivational Climate in Sport Questionniare-2 ............24

Physical Activity in Children Survey................................27

Pedometers..................................................... 28

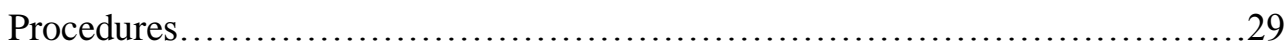

Description of Physical Education Lesson.................................. 30

Data Analysis.........................................................

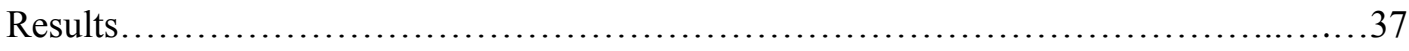

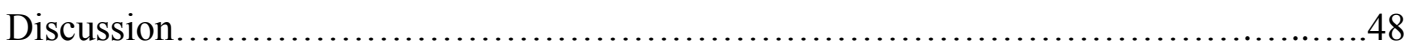

Physical Activity Levels and Enjoyment Levels in Physical Education.............48 
Student Perceived Motivational Climate......................................50

Associations between Variables..........................................51

Physical Activity, Enjoyment and Motivational Climate by Gender, Grade and

Ethnicity......................................................5

Relationship between Mastery Climate, Performance Climate and Enjoyment....53

Relationship between Mastery Climate, Performance Climate and Physical Activity in Physical Education................................................5

Relationship between the Subcategories and Enjoyment........................54

Relationship between the Subcategories and Physical Activity..................55

Limitations..........................................................55

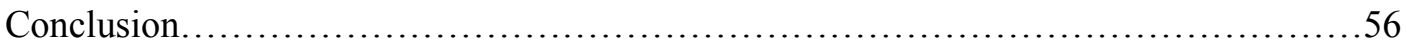

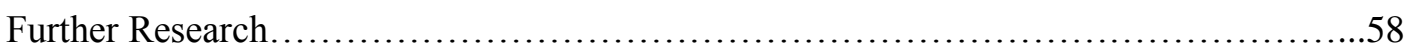

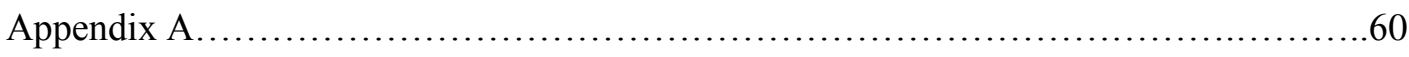

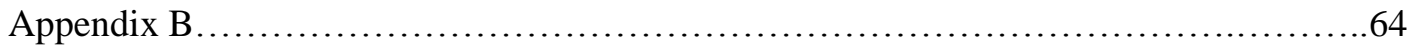

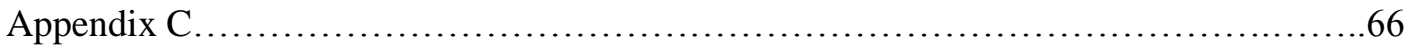

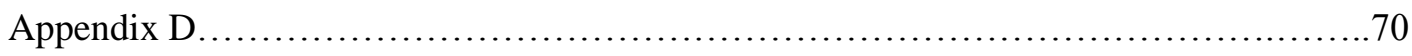

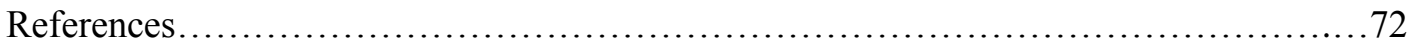

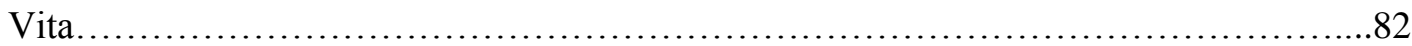




\section{LIST OF TABLES}

Table 1, Regression model results controlling for school, grade, gender, and ethnicity......43

Table 2, Correlations between variables .........................................44

Table 3, Grade means and standard deviations .........................................45

Table 4, Gender means and standard deviations .....................................46

Table 5, Ethnicity means and standard deviations ................................47 


\section{Part I}

\section{The Motivational Climate in Physical Education: A Review of Literature}

Despite the known benefits of regular physical activity (PA) for health and wellbeing, levels of engagement for youth remain low and decline dramatically during adolescence (Belton, O’Brien, Meegan, Woods \& Issartel, 2014). The U.S Department of Health and Human Services (USDHHS) (2010) suggests at least 60 minutes of daily PA can help individuals obtain multiple health benefits such as decreasing the likelihood of developing heart disease, type 2 diabetes, and obesity. Participation in PA is also associated with academic benefits such as improved concentration, memory, and classroom behavior (USDHHS, 2010). Sallis and Owen (1999) identified that PA is directly associated with a longer and better quality of life, reduced risk of a variety of diseases, and many psychological and emotional benefits. With all of the benefits associated with PA still less than $20 \%$ of adolescents, 12 to 19 year olds, self-reported participation in PA for at least 60 minutes in 2009 (USDHHS, 2010). In fact, about one in four adolescents did not engage in 60 minutes of PA on any day of the week. Fairclough and Stratton (2005) and Parish and Treasure (2003) found that PA levels declined as youth aged even though there are abundant opportunities to gain PA throughout the day, however, the opportunity differs by age group. For example, some students may have access to recess, before and after school programs, and intramural sports while other students do not.

\section{Physical Activity Out of School}

One approach aiming to helping all students achieve 60 minutes of PA each day is the Comprehensive School Physical Activity Program (CSPAP) (SHAPE, 2013). The American Alliance for Health, Physical Education, Recreation and Dance, now known as 
the Society of Health and Physical Educators (SHAPE), composed a position statement describing CSPAP as a five component program encompassing PE, staff involvement, PA during school, PA before and after school, and family and community engagement (SHAPE, 2013). The goal of CSPAP is to develop a school culture conductive to promoting lifelong PA across five integral components (Erwin et al., 2013). This program focuses on quality physical education (QPE), PA breaks in the classroom, allotted time of twenty minutes for recess, community partnerships including family involvement, PA before and after school through after school programs or sports participation, among others. The CSPAP information reviewed is mostly geared toward youth aged students and the current study measured PA levels in middle school students. With little information on CSPAP in middle and high school, it is known that teachers can incorporate components of CSPAP such as QPE, staff involvement, PA classroom breaks during school, PA before and after school programs including intramurals, and inviting family and community members to participate in extracurricular events into their school.

\section{Physical Activity Before and After School.}

One area under-recognized for youth to gain PA is before school programs. Erwin et al. (2013) suggest before school programs can contribute to PA for youth, but recognize that afterschool programs are more common. Tudor-Locke et al. (2006) suggest almost half of the daily steps taken by youth are attributed to afterschool activities. Booth and Okely (2005) reported afterschool programs have a great potential for a high impact on youth PA, and that there are multiple physical, cognitive, social, and academic benefits associated with the PA gained in afterschool programs (Sibley \& Etnier, 2003). Beighle et al. (2010) presented strategies and recommendations for 
promoting PA in afterschool settings to help increase PA with the nearly 8.9 million children that attend afterschool programs. Trost, Rosenkranz, and Dzewaltowski (2008) stated that children enrolled in an afterschool program are active 57 percent of the time that is allotted for PA and active at a moderate-to-vigorous level 19 percent of that time.

\section{Family and Community Engagement.}

Youth have the opportunity to be physically active at many different times during their out of school time. Sport participation is one of the most popular forms of activity where youth can attain PA as well as social benefits. The National Council of Youth Sport (NCYS) (2008) reported of the 60 million youth participants, $66 \%$ of boys and $34 \%$ of girls in the United States registered to participate in a sports program. Leek et al. (2011) suggest at a sport practice, youth can gain $75 \%$ of their overall daily PA. Another PA opportunity that up to $84 \%$ of youth do not have is an active commute to school (U.S Department of Transportation, 2009). In 2009 it was reported 44\% of youth rode in cars to school, $40 \%$ rode the school bus, $12 \%$ walked, $3 \%$ listed other, and $1 \%$ rode a bike; however, once at school, youth have various opportunities to accumulate PA in PE, recess, lunch, and classroom activity breaks (U.S Department of Transportation, 2009).

\section{Staff Involvement.}

One component of CSPAP is getting staff involved with physical activities through wellness programs. The overall goal is to reduce healthcare costs. Wellness programs have shown to be successful by benefiting financially (Aldana, Merrill, Price, Hardy, \& Hanger, 2005), but some employees find it difficult to find the time to participate. 


\section{Physical Activity in School}

\section{Physical Activity During School.}

During the school day, youth can accumulate PA in a number of areas including PE, classroom activity breaks, recess, and before and after school programs. Recess and lunchtime PA breaks have been identified as important sources of PA for youth. TudorLocke et al. (2006) reported recess could account for 8-9\% of overall PA per day, while Erwin et al. (2012) suggested youth can attain between 17-44\% of school day PA from participating in a 15-minute recess period. The built environment could help increase recess PA levels by incorporating playground markings such as foursquare lines or mural-type paintings (Ridgers, Stratton, Fairclough \& Twisk, 2007) or installing playground structures (Farley, Meriwether, Baker, Rice, \& Webber, 2008). Tudor-Locke et al. (2006) suggest lunchtime PA can represent even more PA than recess at up to 15$16 \%$ of overall PA for the day. Lunchtime PA can vary from recess PA by the amount of time allotted and the frequency at which it occurs.

Classroom activity breaks are an opportunity when youth can gain sufficient PA. Erwin et al. (2009) demonstrated students in a math class which integrated PA gained up to 692 steps for one break, accounting for an overall $5 \%$ of the daily recommendation for youth. Classroom activity breaks are positively associated with increased reading comprehension (Uhrich \& Swalm, 2007), on task engagement (Mahar et al., 2006), and improved classroom behavior (Mahar et al., 2006). Classroom activity breaks should be content rich and specifically related to a learning outcome to be most beneficial (Erwin, Beighle, Carson \& Castelli, 2013). 


\section{Physical Education in School.}

While other areas in the school environment provide PA opportunities, the foundation for CSPAP, and school based PA promotion, is PE. Fairclough and Stratton (2005) explain PE has limited potential to significantly contribute to the daily PA levels of most young people because of the infrequent amount of time spent in PE. However, Tudor-Locke et al. (2006) suggest differently reporting that PE can contribute $8-11 \%$ of overall PA per day for $6^{\text {th }}$ grade students. In addition, $\mathrm{PE}$ is able provide students with skills knowledge and attitude to be active for a lifetime.

While the SHAPE reported 84\% of middle schools required PE in the US in 2011, the Centers for Disease Control and Prevention (CDC) reported in 2006, only 2\% of high schools, $8 \%$ of middle schools, and $4 \%$ of elementary schools nationwide provided daily PE (CDC, 2010). The School and Health Policies and Program Study (2007) reported 15.2\% of middle schools nationwide offered PE at least three days per week or its equivalent for the entire year. Specific to this study, the CDC (2009) revealed $45.5 \%$ of middle school students in Kentucky attended daily PE class. In addition, an average of 17.6\% of Kentucky middle school students are obese (CDC, 2010).

With no recess offerings in middle school, limited amount of visits to PE during the school year, and youth sport participation declining (NCYS, 2008), it is important to have high moderate to vigorous physical activity (MVPA) time while in PE class. One goal recognized by SHAPE is for students to be physically active for at least $50 \%$ of class time (SHAPE, 2013). Activities equivalent in intensity to brisk walking or bicycling are considered moderate physical activities, while activities that increase breathing and heart rate, such as jogging, are vigorous physical activities. 
$\mathrm{PE}$ is one area in which children can receive valuable amounts of PA; however, some PE teachers are struggling to maximize PA. Some of this could be attributed to not addressing or considering student motivation and attitudes towards PA. With such a wide discrepancy in MVPA levels between students, it is possible that physical educators teach to the class as a whole without planning adequately for individual differences (Metzler, 1989). Parish and Treasure (2003) stated middle school students only had $16.4 \%$ of MVPA participation of total class time. McKenzie and colleagues (2006) reported adolescent girls engaged in MVPA during 37.9\% of class time which resulted in 13.9 minutes per lesson. One intervention by McKenzie and colleagues (2004) that had drastically different percentages of MVPA described middle school PE being below the desired 50\% of class time spent in MVPA, however after participation in the intervention, schools ended with 52\% of MVPA time while the nonintervention schools were in MVPA about $48 \%$ of the lesson. Jooycon (2013) suggests one strategy that could make a significant contribution to individual PA levels would be to alter teaching strategies, specifically effective activity selection, class organization, management and instruction focusing on increasing PA levels to meet the national goal of 50\% PA in PE.

Parish and Treasure (2003) reported a noticeable decline of PA in PE from 6th to 8th grade, particularly in female students. Papaioannou (1995) revealed as children get older, they also show decreasing scores on effort and enjoyment of the lesson, feel less competent, become less task-involved and their exercise frequency decreases. Duda (1996) hypothesized that curricula based almost exclusively on competitive activities or on a sport education model will decrease the motivation of students with low athletic ability. Brown and Grineski (1992) add many students may feel incompetent or 
unpleasant when they are asked to compete. Since competitive activities do not ensure equal opportunities for learning for every student (Graham, 1992) and may not contribute to the learning process, what can physical educators do to create an environment that emphasizes the learning process, and in turn, increase students' motivation? Ntoumanis and Biddle (1999) recommend creating a mastery climate, which promotes learning, effort, and self-improvement by the teacher, because of its ability to positively influence the effort, persistence, cognitions, emotions and behavior of individuals in PA contexts and are established by a group leader such as a teacher.

\section{Physical Activity in Physical Education.}

Fairclough and Stratton (2005) reviewed forty studies reporting PA during middle and high school PE in which heart rate (HR) monitors, systematic observation and accelerometry were used to measure PA. They reported students in nonintervention conditions using HR monitors were engaged in MVPA for $37.9 \pm 14.6 \%$ of class time, students in nonintervention conditions using systematic observations were engaged in MVPA for $26.6 \pm 15.2 \%$ of class time, and students in nonintervention conditions using accelerometry engaged in MVPA for $46.8 \pm 13.9 \%$ of class time. Overall, students were active in the moderate to vigorous range between $27 \%$ and $47 \%$ of time.

Nader (2003) demonstrated through rigorous direct observation methods, specifically SOFIT, that students spent $37 \%$ of class time above a moderate intensity level in PE. Tudor-Locke et al. (2006) suggested that a 30-minute PE class can contribute $8-11 \%$ of overall PA per day for $6^{\text {th }}$ grade students. This aligns with Wickel and Eisenmann's (2007) findings suggesting that PE could account for up to12\% of daily PA, and Morgan et al. (2007) reporting PE can contribute up to $18 \%$ of a low-active child's 
recommended daily PA. McKenzie et al. (2006) provided data suggesting girls spent an average of $37.9 \%$ of class time engaged in MVPA totaling nearly 13.9 minutes per lesson. There is strong evidence that PE is a vital area in which both boys and girls can gain valuable PA.

The review by Fairclough and Stratton (2005) also examined the type of PE activity being taught. They grouped activities according to common characteristics. For example, basketball and soccer were classified as team invasion games while gymnastics and dance were classified as movement activities. The review suggests the highest levels of MVPA are in fitness-oriented and team invasion games (48\% and 46\% MVPA, respectively). The lowest levels reported were in a track and field unit when the lesson focus was on jumping (7.2\%-25.5\% MVPA); however, higher levels of MVPA were reported when the lesson focus was on running $(27.6 \%)$.

In addition to nonintervention MVPA and type of activity, this review analyzed gender MVPA difference in twenty-one studies. The data examined suggest that males engaged in MVPA between $16 \%$ and $61 \%$ of class time. Females were slightly lower, with MVPA levels between $16 \%$ and $57 \%$ of class time. Fairclough and Stratton (2005) acknowledge boys' and girls' MVPA levels were similar because PE offers similar opportunities for boys and girls to be active. Reasoning for the difference in MVPA levels might be explained by personal opinions on the type of activities in which the participants took part.

Parish and Treasure (2003) also completed a study that analyzed PA by gender in addition to perceived ability and the student perceived motivational climate. The participants included 452 middle school PE students in the western region of the United 
States. They reported a noticeable decline of PA from 6th to 8th grade, particularly in female students. Sallis (2000) indicates this decline could be a result of a combination of biological, social, psychological, and environmental factors. When examining the PA levels of adolescents in PE and during school, it is important to examine other factors impacting their PA. Age, gender, and ethnicity are known to impact daily or habitual PA of this population.

\section{Age and Physical Activity}

As students age, PA appears to decline. Duke and colleagues (2003) asked participants, ranging in age from 9-13 years old, to recall the past seven days of their PA for organized PA and free time PA. The 9 year olds participated in organized PA $36.1 \%$ of the time, 10 year olds participated in organized PA 37.5\%, 11 year olds participated in organized PA 43.1\%, 12 year olds participated in organized PA 37.7\%, and 13 year olds participated in organized PA $38.1 \%$. The 9 year olds participated in free time $75.8 \%$ of the time, 10 year olds participated $77 \%$ of the time, 11 year olds participated $78.9 \%$ of the time, 12 year olds participated $77.5 \%$ of the time, and 13 year olds participated $78 \%$ of the time. These findings are slightly different when compared to other studies such as Fairclough and Stratton (2005) and Parish and Treasure (2003), which demonstrated that PA levels declined as youth age. Troiano and colleagues (2007) completed a study to describe PA levels in children ages 6-11 years old, adolescents ages 12-19 years old, and adults ages 20 and older. This study used accelerometers to measure PA levels in 6,329 participants who provided one day of data and 4,867 participants who provided four or more days of data from a noninstitutionalized population in the US. Results revealed males are more active than females, PA declines from childhood, 6 to 11 years old, to 
adolescence, 12 to 19 years old, and then continues to decline with age. For example, $42 \%$ of children reached the recommended 60 minutes of PA per day while only $8 \%$ of adolescents achieved the same recommended goal (Troiano et al., 2007). An interesting finding suggests PA collected via accelerometer was much lower than that of self-report.

\section{Ethnicity and Physical Activity}

Ethnicity may also be a contributor to declining PA levels in students. Duke and colleagues in association with the CDC (2003) had 9-13 year olds complete a parent and student questionnaire related to participation in organized and free time PA. Their findings suggest $38.6 \%$ of girls and $38.3 \%$ of boys participated in organized PA during the last seven days; $74.1 \%$ of girls and $80.5 \%$ of boys participated in free time PA during the last seven days.

Additionally, 24.1\% of Black, non-Hispanic individuals participated in organized PA during the last seven days, $25.9 \%$ of Hispanic individuals participated in organized PA during the last seven days, $46.6 \%$ of White, non-Hispanic individuals participated in organized PA during the last seven days, and $74.7 \%$ of Black, non-Hispanic individuals participated in free time PA during the last seven days. Furthermore, 74.6\% of Hispanic individuals participated in free time PA during the last seven days, 79.3\% of White, nonHispanic individuals participated in free time PA during the last seven days. While acknowledging that past studies have shown that Caucasians are more physically active than other ethnicities, Sheng and Gao (2012) found Hispanic middle-school girls had more daily steps and PA time than Caucasian girls. They did not find any other significant differences between ethnicities. Reasons for the differences in their results from those of the CDC could be contributed to the use of pedometers in this study versus 
self-reporting to the CDC. The CDC (2005) suggests Caucasian males are the most active, followed by Hispanic males, African American males, Caucasian females, Hispanic females and lastly, African American females. When controlling for gender, Caucasians are the most active followed by Hispanic and African American. Ethnic differences could result from a complex interaction between socioeconomic, environmental, and cultural findings (Sheng \& Gao, 2012).

\section{Gender and Physical Activity}

Gender is one area that has been identified as a contributor to student PA levels. Wickel and colleagues (2007) examined day-to-day PA in 1,443 children aged 6-12 years old in three countries including the United States. The children wore a pedometer for four consecutive weekdays, and daily differences were calculated for each individual to describe variability. Results indicated mean steps were higher among boys $(14,698 \pm$ 3,373 steps/day) than girls $(12,086 \pm 2,929)$. These results align with the findings from Currie et al. (2008) and Duncan et al. (2007) that typically boys are more active than girls. Fairclough and Stratton (2005) analyzed gender MVPA difference in 21 studies. The data examined suggest that males engaged in MVPA between $16 \%$ and $61 \%$ of class time. Females were slightly lower, with MVPA levels between $16 \%$ and $57 \%$ of class time. Fairclough and Stratton (2005) acknowledge boys' and girls' MVPA levels were similar because PE offers similar opportunities for boys and girls to be active. Reasoning for the difference in MVPA levels might be explained by personal opinions on the type of activities that the participants took part in.

To summarize, there are various opportunities to gain PA throughout the school day. Youth might have more opportunities, but while in school adolescents can gain daily 
PA with classroom activity breaks, before and after school programs and intramurals, any free time associated with lunch, and most importantly in a QPE program. While students are participating in a QPE program, one motivational theory to incorporate into that program could be the Achievement Goal Theory (AGT).

\section{Achievement Goal Theory}

Sallis and colleagues (2000) suggest motivation is considered an influential variable for PA participation. Two social-cognitive theories used to examine PA and motivation are the Self-Determination Theory (SDT) and the Achievement Goal Theory (AGT). The SDT suggests autonomy, perceived competence, and social relatedness is needed for the positive development of motivation (Deci \& Ryan, 1985). The AGT suggests student perceived motivational climate can influence PA levels, student enjoyment and intrinsic motivation. AGT is used when evaluating student motivation because it takes into account the orientation of the student toward the task and the climate which is also known as the learning environment. The AGT examines how individuals cognitively process and develop their views about achievement under various social contexts and influences (Roberts, 1992; Bandura, 1997). According to this approach, two achievement goals prevail in achievement goal settings, such as PE. These two goals perspectives were first labeled learning and performance by Dweck and Elliot (1983), then task involved and ego involved by Nicholls (1984), and mastery and ability focused by Ames and Archer (1988). For the purposes of this paper, ego and task involved will be utilized for consistency purposes. 


\section{Ego- and Task-Involving Goals}

Nicholls (1989) described ego-involving goals as focusing on outperforming others and claiming success with little effort. Parish and Treasure (2003) explain a student in a performance involvement state demonstrates ability by exceeding the performance of other classmates. Nicholls (1989) described a task-involving goal as an individual focusing on improving competence, feeling satisfied when new skills are developed, placing a high value on effort, and viewing mistakes as part of the learning process. Parish and Treasure (2003) explain a student in a task involving state demonstrates ability through the learning and mastery process and when high effort is exerted. In this theory, it is possible for individuals to be high or low in both orientations, or high in one while low in the other orientation. Task involved students in PE showed increased leisure-time PA (Papaioannou, Bebetsosa, Theodorakisb, Christodoulidisa, \& Koulia, 2006), while ego involved students and PA related outcomes had mixed findings (Roberts, Treasure, \& Conroy, 2007).

\section{The Climate}

Vazou, Ntoumanis, and Duda (2005) describe the term motivational climate as the students' perception of the motivational cues and expectation that the teacher places upon the class. The motivational climates focus upon how success is defined, how students are evaluated, what is recognized and valued, and how mistakes are viewed. There are two classifications identified under the motivational climate: mastery-oriented motivational climate and performance-oriented motivational climate. Ntoumanis and Biddle (1999) suggest motivational climates can be established by group leaders, such as a PE teacher, and can influence the effort, persistence, cognitions, emotions and behavior of 
individual's PA behavior. Ntoumanis (2001) reported that positive social factors by the teacher, such as promoting cooperative learning, emphasis on individual improvement, and changes in task, can allow for positive motivational results in PE.

Performance climate. A performance-oriented climate emphasizes high ability, competition, winning and positive social comparison (Ames, 1992). In this climate, a teacher would emphasize the importance of outperforming peers or surpassing normativebased standards. For example, a student might perceive the teacher encouraging the class or star students to outperform other classmates in order to feel successful during a shooting activity in a basketball unit. Competition is highly emphasized by high levels of traditional game play. This leads to a competitive environment and has been found to alienate less-skilled students (Bevans et al., 2010). Unfortunately, in a performance climate, only limited students receive positive feedback (Dweck, 1986), and the focus is on competition and viewing mistakes as failures (Ames, 1992).

Weiss and colleagues (2000) suggest youth ages 10-15 years old become more competitive and seek to do better than the same-age person. In addition, students in a performance climate have been associated with showing lack of enjoyment and high anxiety. Dweck and Leggett (1988) also described students in PE as having decreased motivation and even learned helplessness, or giving up quickly because a student feels success or failure is out of their control, when placed in a performance climate. Nicholls (1989) described a performance climate as demonstrating high ability by winning with minimized effort. Papaioannou and Kouli (1999) found that the perception of a performance-involving climate was linked to higher levels of somatic anxiety, or anxiety provoked by tension. Papaioannou (1995) also found a performance climate causing a 
decrease in intrinsic motivation in students. When students complete a questionnaire about the perceived motivational climate, sub-scales for the performance climate could include punishment for mistake, unequal recognition, and team rivalry.

Mastery climate. Weiss (2000) described in The President's Council on Physical Fitness and Sports that a mastery climate in PE emphasizes cooperative learning and diverse ability groups that lead to positive peer relationships, enhancing peer acceptance, and creating opportunities for close friendship development (Weiss, Corbin, \& Pangrazi, 2000). In addition to less-skilled students, girls and overweight students preferred more cooperative activities or non-competitive ones outlined in a mastery climate (Brenstein, Phillips \& Sliverman, 2011). Nicholls (1989) described that all students perceive a mastery climate until the ages of 10 to 12 because they cannot comprehend that effort does not equal ability. Bevans and colleagues (2010) found that a perceived mastery climate can enhance student engagement and increase skill development in students who have a lower perceived competence.

In a mastery climate, the teacher stresses that success is based upon personal improvement and effort. This climate values the learning process, and achievement is based on self-referenced standards. This allows more frequent opportunity for related feedback regardless of ability level (Ames, 1992). Ntoumanis and Biddle (1999) stated PE students perceiving a mastery climate also reported higher enjoyment, higher perceived competence and beliefs that effort leads to success. Duda (1996) suggests a high mastery-involving climate positively relates to students' intrinsic motivation in PE. Mitchell (1996) also revealed an increase in student intrinsic motivation when a mastery climate is perceived in PE. When students complete a questionnaire about the perceived 
motivational climate, sub-scales for the mastery climate could include effort/improvement, cooperative learning, and important role.

TARGET. Weiss and colleagues (2000) suggest one way to enhance PA in youth is to create a mastery motivational climate using TARGET (Task, Authority, Recognition, Grouping, Evaluation, Timing) structures. TARGET offers strategies to help meet the PA recommendation set by Strong et al. (2005), describing that schoolaged youth should participate in PA that is developmentally appropriate, enjoyable, and involves a variety of activities.

TARGET is a motivational model with six principles including task, authority, recognition, grouping, evaluation, and time. Epstein (1989) describes each, in order, as task variety and optimal challenges, opportunities for choice and shared decision-making, recognition of effort and self-improvement, partner and small-group problem-solving tasks, evaluation criteria focused on self-references standards, and adequate time for learning and demonstrating skills. Later, Ames (1992) developed strategies within the TARGET framework for identifying instructional practices associated with a mastery or performance climate. When these six structures are used correctly, it creates a mastery climate which emphasizes the learning process versus the product within the participants which should increase intrinsic motivation and enjoyment.

Epstein (1989) created TARGET for classifying key dimensions of the learning environment to promote a mastery motivational climate in a physical activity context. By manipulating the TARGET structures to support the development of a mastery-oriented climate, the teacher promotes self-referenced goals, student leadership roles that include decision-making, private recognition of improvement and effort, mixed ability and 
cooperative groups, scores based on improvement and effort, and maximum time for task completion. In addition, Bowler (2009) found MVPA levels to increase, specifically task, recognition and evaluation, during an intervention study focusing on creating a mastery climate using the TARGET structures. TARGET emphasizes a mastery climate where students would work at their own level on a variety of tasks, have decision making opportunities, work in small groups that include mixed ability, have maximum practice time, value the learning process, and receive feedback related to effort and improvement. Practical strategies for applying the TARGET principles should be applied in PE in order to enhance PA for students according to findings from Bowler (2009).

\section{Motivational Climate Research}

Parish and Treasure (2003) completed a study that analyzed PA by gender in addition to perceived ability and the student perceived motivational climate. The participants included 452 middle school PE students in the western region of the United States. They reported both male and female students PA levels declined from $6^{\text {th }}$ to $8^{\text {th }}$ grade, more so in females. Sallis (2000) indicates this decline could be a result of a combination of biological, social, psychological, and environmental factors. In addition to gender differences in PA levels, Sallis (2000) discuss perceptions of a masteryoriented motivational climate to be positively related to PA behavior. As a result, they conclude this study can provide insight on how physical educators may positively affect all students' motivation and activity levels. They did not find a relationship between perceptions of a performance climate in PE and PA.

Casey and colleagues (2009) conducted semi-structured interviews with 34 female participants, ages 12-13 years old, enrolled in rural PE classes. After data analysis 
was completed by transcribing the focus group interviews and finding themes, results revealed two main themes. The participants identified being task-involving goal oriented by increasing enjoyment through trying new things, and ego-involved goal oriented by wanting to keep fit and healthy. In this study, participation in sport and PA increased when participants perceived high self-competence. An interesting finding indicated that the female participants felt attaining outcome goals such as competition, success, and peer recognition increased their self-competence, enjoyment, and the likelihood of maintaining participation. However, when peers teased them, their enjoyment and selfcompetence decreased. When asked about the PE climate, the participants outlined both positive and negative experiences that occurred while in PE. Positive influences on the girls' participation were associated with positive teacher feedback, when teachers acted as physically active role models, and when new skills were learned. Negative influences on the girls' participation were associated with negative teacher feedback, coeducational PE classes, and male PE teachers.

White and colleagues (1998) examined the relationship between goal orientation and perceptions of the motivational climate in a sports setting and a PE class with 132 participants from 10-14 years old. These participants were enrolled in a PE class and participated on at least one organized sports team. They used the Perceived Motivational Climate in Sport Questionnaire 2 (PMCSQ-2) in PE to measure perceptions of the motivational climate emphasized by the PE teacher. Results suggest there was a significant gender difference, meaning males and females have different achievement motivation patterns for dispositional goals as well as the perceptions of the motivational climate. 
Carr and Weigand (2008) examined the interactive effects of children's multiple goal profiles and perceptions of the motivational climate with 429 students in northwest England. A MANOVA was used to identify significant relationships for goal profiles and perceived motivational climate. Results from the PMCSQ-2 revealed students with a high mastery and high performance profiles had higher levels of intrinsic motivation, but really all other profiles such as high mastery/low performance, low mastery/high performance, and low mastery/low performance also had higher levels of intrinsic motivation due to exposure of a perceived mastery climate. Students could have been exposed to a mastery climate at any point throughout their time in k-12 PE.

Overall, it is beneficial for PE teachers to create a mastery climate for their students. Higher perceptions of a mastery climate can produce higher levels of enjoyment, intrinsic motivation, and perceived competence while in PE. This study is necessary to identify relationships at the middle school level between the motivational climate, enjoyment and PA levels.

The purpose of this study is to determine if student perceived motivational climate predicts enjoyment and PA levels while controlling for school, gender, grade, and ethnicity in middle school PE.

\section{Hypotheses}

1. It is hypothesized that current physical activity levels will decline with grade, be lower in females than males, and be lower in minority students.

2. It is hypothesized that current enjoyment levels will decline with grade, be lower in females than males, and be lower in minority students.

3. It is hypothesized that the students will perceived a mastery motivational climate overall. 
4. It is hypothesized that the mastery climate, enjoyment, physical activity, effort/improvement, cooperative learning, and important role to be positively correlated with each other and negatively correlated with performance climate, punishment for mistake, unequal recognition, and team rivalry will be negatively correlated.

5. It is hypothesized that physical activity and enjoyment will differ by grade and gender with a mastery climate perceived, but no difference will arise between ethnicities.

6. It is hypothesized that there will be a significant positive relationship between mastery climate and enjoyment and a significant negative relationship between performance climate and enjoyment, while controlling for school, gender, grade, and ethnicity.

7. It is hypothesized that there will be a significant positive relationship between mastery climate and physical activity and a significant negative relationship between performance climate and physical activity, while controlling for school, gender, grade, and ethnicity.

8. It is hypothesized that there will be significant positive relationships between effort/improvement, cooperative learning, important role with enjoyment, and significant negative relationships between punishment for mistake, unequal recognition, and team rivalry with enjoyment, while controlling for school, gender, grade, and ethnicity.

9. It is hypothesized that there will be significant positive relationships between effort/improvement, cooperative learning, important role with physical activity, and significant negative relationships between punishment for mistake, unequal recognition, and team rivalry with physical activity, while controlling for school, gender, grade, and ethnicity. 


\section{Part II}

\section{Descriptive Analysis of the Student Perceived Motivational Climate, Enjoyment, and Physical Activity in Middle School Physical Education \\ Background}

Current recommendations suggest that youth should participate in PA for at least 60 minutes per day (SHAPE, 2013). Research shows that many children are not meeting the recommended time (USDHHS, 2010). In addition, there is a decline in PA during adolescence, specifically during the middle school years (Parish \& Treasure, 2003). For instance, what type of motivational climate has the most positive impact on PA levels and enjoyment during PE? This information would be useful in explaining to PE teacher how to help increase PA levels and enjoyment in these populations. Whitt-Glover and colleagues (2009) suggest that more studies are needed examining what influences PA decisions for subgroups such as girls and minorities.

At school, students have the opportunity to be physically active throughout the day. While students can participate in before school programs, PA classroom breaks, recess, lunch free time, $\mathrm{PE}$, and afterschool programs, these programs vary in availability from school to school. The amount of PA differs so much between each student for various reasons. For example, $44 \%$ of youth ride in cars to school and $40 \%$ ride the school bus, while only $12 \%$ walk and $1 \%$ ride a bike. Based on this information, majority of students will miss out on the before school PA commute opportunity (U.S Department of Transportation, 2009). If the teacher does not provide classroom PA breaks, the student may miss out on up to 5\% of overall steps for the day (Erwin, Abel, Beighle, \& Beets, 2009). If recess is taken away or unavailable, students could miss out on $8-11 \%$ of overall daily steps (Tudor-Locke, Lee, Morgan, Beighle \& Pangrazi, 2006). It is 
suggested if the PE teacher does not create a mastery climate that focuses on enjoyment and $50 \%$ of time spent being PA, students could lose up to $12 \%$ of overall steps (Wickel \& Eisenmann, 2007). Finally, Tudor-Locke et al. (2006) suggest almost half of the daily steps taken by youth are attributed to afterschool activities. If the student is not involved in an after school program or organized sport, the student could miss half of the overall steps they could accumulate. It is important to reiterate that adolescents may not have all of the opportunities that youth have to accumulate PA throughout the day.

\section{Achievement Goal Theory}

While in PE, the Achievement Goal Theory (AGT) is often used when evaluating student motivation as it takes into account the orientation of the student toward the task and the climate, or the learning environment. The AGT examines how individuals cognitively process and develop their views about achievement under various social contexts and influences (Bandura, 1997; Roberts, 1992). According to this approach, two achievement goals prevail in achievement goal settings, such as PE: ego-involving and task-involving.

Ego-involving goals focus on outperforming others, claiming success with little effort, and having high perceived ability, while task-involving goals focus on improving competence, feeling satisfied when new skills are developed, placing a high value on effort, and viewing mistakes as part of the learning process (Nicholls, 1989). The motivational climate is the students' perception of the motivational cues and expectation that the teacher places upon the class. The motivational climates focus upon how success is defined, how students are evaluated, what is recognized and valued, and how mistakes are viewed. A performance-oriented climate emphasizes high ability, competition, 
winning and positive social comparison (Ames, 1992), while a mastery climate emphasizes cooperative learning and diverse ability groups that lead to positive peer relationships, enhancing peer acceptance, and creating opportunities for close friendship development (Weiss, Corbin, \& Pangrazi, 2000).

Little research has been conducted on student perceived motivation climate and its relationship with enjoyment and PA levels in PE. Parish and Treasure (2003) suggest perceptions of a mastery-oriented motivational climate to be positively related to PA behavior after completing a study with middle school aged students. They did not find a relationship between perceptions of a performance climate in PE and PA. White and colleagues (1998) found a significant gender difference, meaning males and females have different achievement motivation patterns for dispositional goals as well as the perceptions of the motivational climate. Carr and Weigand (2008) found students with high mastery and high performance profiles had higher levels of intrinsic motivation, but other profiles such as high mastery/low performance, low mastery/high performance, and low mastery/low performance also had higher levels of intrinsic motivation due to exposure of a perceived mastery climate. The research in this area is inconclusive, suggesting that more research is needed. Thus, the purpose of this study is to determine if student perceived motivational climate predicts enjoyment and PA levels while controlling for school, gender, grade, and ethnicity in middle school PE.

\section{Methods}

\section{Participants and Setting}

Participants included 290 students $\left(n=1086^{\text {th }}\right.$ grade students, $n=947^{\text {th }}$ grade students, $\mathrm{n}=888^{\text {th }}$ grade students, $\mathrm{n}=140$ male, $\mathrm{n}=150$ female) from three middle 
schools in the same school district in the southeast United States. The ages of participants ranged from 11 to 14 years old. The schools were selected because they allowed for a diverse sample of ethnicities among participants. School $1(n=188)$ was comprised of 952 students with $61 \%$ of the population Caucasian, 26\% African American, 5\%

Hispanic, and $8 \%$ Other. School $2(n=64)$ was comprised of 682 students with $26 \%$ of the population Caucasian, 33\% African American, 39\% Hispanic, and 2\% Other. School $3(n=38)$ was comprised of 586 students with $47 \%$ of the population Caucasian, $36 \%$ African American, 11\% Hispanic, and 6\% Other. This sample was comparable to the school population. The ethnic breakdown was 21\% African American, 13.8\% Asian, 15.5\% Hispanic, 52\% White, and 7.0\% Other. Students were in their third quarter while data were being collected. Students at all three schools would have had their PE teacher for at least half of the year, $7^{\text {th }}$ and $8^{\text {th }}$ graders would have had them in pervious years.

\section{Measures/Instruments}

Three instruments were utilized for data collection for this study: (a) a motivational climate in physical education questionnaire, (b) a physical activity enjoyment questionnaire, and (c) pedometers. Information about each instrument is provided below. Procedures for each of the instruments are provided in the next section.

Perceptions of Motivational Climate in Sport Questionnaire-2 (PMCSQ-2).

This scale measures the perception of mastery and performance motivational climates (Newton, Duda, \& Yin, 2000). The format utilized was a 33-item, 6-factor solution including three task-involving subscales (effort/improvement, important role, and cooperative learning) and three ego-involving subscales (intra-team member rivalry, unequal recognition, and punishment for mistake). The questions were arranged in a 5- 
point Likert scale ranging from 1 (strongly disagree) to 5 (strongly agree). Following is a thorough report of validation and reliability studies completed previously on the PMCSQ.

The PMCSQ was initially developed by Seifriz et al. (1992) to assess athletes' perceptions of the prominent motivational climate goal structures created by their coach. Seifriz et al. (1992) and Walling et al. (1993) reported findings suggesting support for the reliability and concurrent validity of the PMCSQ. However, both also indicated the PMCSQ could be strengthened by conceptualizing the motivational climate in a hierarchical manner with subscales underlying the higher-order Task-Involving and EgoInvolving scales. In 2000, two studies were performed to test the validity and reliability of the revised PMCSQ and examine the development of a multi-dimensional hierarchically structured measurement (Newton, Duda, \& Yin, 2000). This questionnaire has been revised by an expert panel and contained a pool of an additional 300 items.

From there, a 63-item questionnaire was administered to 201 female volleyball and basketball players from 21 high school and collegiate teams in the USA. In total, 12 high school basketball teams, two college basketball teams, six college volleyball teams and one high school volleyball team participated. The players' mean age was 16.4 and ranged from 13-23 years old.

Following the first study, the 63-item questionnaire was reduced to a 30-item questionnaire. The second study aimed to test the concurrent validity and internal reliability of the PMCSQ-2 and examine its factor structure using confirmatory factor analysis. Researchers wanted to know how to conceptualize the motivational climate and determine how well the PMCSQ-2 measured the motivational climate as conceptualized in the models. The second assessment of the PMCSQ-2 had 385 female volleyball players 
recruited from 45 junior volleyball teams. The players were aged from 14-18 years old. Based off the results from the second study, the researchers dropped one question and added two items from the Important Role subscale and two items from the Cooperative Learning subscale, finalizing it to 33 -items. The items added were "On this team, the coach believes that all the players are crucial to the success of the team," "On this team, each player feels as if they are an important team member," "On this team, the players really work together as a team," and "On this team, the players help each other to get better and excel." The purpose of study two was to further refine the questionnaire and explore the structure, reliability and validity.

In study 2 confirmatory factor analysis was used to test the proposed hierarchical model structure in a study completed on 385 American female volleyball players with a mean age of 15.2 years old. Findings revealed an acceptable internal consistence for the task-involved higher order scale and similar findings were reported for the ego-involving higher-order scale. The PMCSQ-2 is designed on a 5-point Likert-type scale 1 (strongly disagree) to 5 (strongly agree). The PMSCQ-2 was created to measure athletes' perceptions of their environment; however, the instrument has been used in K-12 PE setting by Gonzalez-Cutre, Scicilia, Moreno, \& Fernandez-Balboa (2009) and by Ntoumanis (2002).

One concern with the PMCSQ-2 is the subscale of intra-team rivalry and if it exists in PE. It is believed the students will have the opportunity to experience this subscale because of the traditional team sports units being taught. An additional concern arises with this subscale from study 2 by Newton and colleagues (2000) reporting problematic internal consistency. One explanation may be the coaches and participants 
were female. Because of this, it could have been less likely to provide and participate fully in intra-team rivalry training drills and interactions. In addition to the concern of intra-team rivalry, certain portions of this questionnaire were changed for this particular study. For instance, "On this team" was changed to "In this class," the leader identified as "coach" was changed to "teacher," "teammates" was changed to "classmates," and "players" was changed to "students."

The PMCSQ-2 was necessary for this study because it fully assessed the two higher-order factor structures, being mastery oriented climate and performance oriented climate, in addition to the six subscales, in a sport setting. It was believed that all of the subscales, effort/improvement, important role, and cooperative learning, intra-team member rivalry, unequal recognition, and punishment for mistake, would contribute to students' PA levels in PE. The PMCSQ-2 was used to assess participants' perceptions of the mastery and performance-oriented motivational climate. A copy of the PMCSQ-2 and the coding information has been included in Appendix A.

Physical Activity in Children Enjoyment Survey (PACES). Student enjoyment in PE was assessed using the PACES survey (Motl et al., 2001). The original scale was designed to measure positive affect associated with involvement in physical activities in college students (Kendzierski \& DeCarlo, 1991). The PACES was revised by Crocker et al. (1995) to be used with 12-16 year olds. Motl et al. (2001) also modified the PACES for use with young adolescent females. Results indicated that the PACES survey displayed good internal consistency and item-total correlations. The findings suggest support for the PACES as a valid measure of enjoyment in PA in children (Moore et al., 2008). The PACES scale included 16 statements in Likert type format with responses 
ranging from 1 (Disagree a lot) to 5 (Agree a lot). Statements included "I enjoy it" to "It makes me depressed." Responses are averaged after negative statements were reverse coded and higher scores indicate higher levels of enjoyment. A copy of the PACES scale is included in Appendix B.

Pedometers. Pedometers are small digital devices that detect steps by responding to vertical accelerations (Welk, 2002). Most pedometers record steps taken and activity time while some pedometers also record moderate to vigorous PA time. Pedometers are popular for the objective measurement of PA because they are relatively inexpensive and unobtrusive in addition to being relatively accurate (Le Masurier, 2004; Le Masurier et al., 2004; Le Masurier \& Tudor-Locke, 2003; Tudor-Locke \& Myers, 2001; Schneider et al., 2003). The Walk4Life pedometer was selected because it was considered an accurate and appropriate motion sensor for research with children (Beets, Patton, \& Edwards, 2005). Pedometers are lightweight, cost effective, and easy to conceal because of the built-in clip, however, they do have limitations. These limitations include lack of measurement during a time of PA when the individual has no vertical accelerations to detect such as bicycling and swimming. Similar to the Parish and Treasure (2003) study, 3 to 4 days of data collection were used in this study. Vincent and Pangrazi (2002) reported 3 to 4 days of data collection were sufficient to determine habitual activity levels. Procedures for the pedometers are reported below. The total activity time was used to prevent differences in step count based on differences in class length; this allowed the researcher to determine a percentage of activity time. Following inputting the data into Excel, the total steps per minute was calculated by using the formula $=($ cell 
number)/time of class. The percentage of time active was calculated by using the formula $=($ HOUR $) /$ cell number.

\section{Procedures}

Once approval was obtained from the University of Kentucky Office of Research Integrity, the school district, each school's principal, and each PE teacher at the participating schools, the researcher distributed parent consent (Appendix C) and student assent forms (Appendix D) to the eligible students at their school. Only students enrolled in PE were eligible for this study. Each student had a two week period to return the signed consent form. Each returned consent form was checked off on the attendance sheet and kept in a folder specific for that class. Once the two week period was over, the researcher assigned corresponding numbers to each participating student based on returned consent forms. Each participant was provided a pedometer, which was labeled with an ID to be traced back to the participant name. Trained graduate student researchers were present for each lesson that involved collecting data. All researchers were trained on procedures such as handing out pedometers, collecting pedometers, recording activity time and step count, and administering the questionnaire. At the beginning of each PE class the pedometers were zeroed out by the researcher, pressing the reset button for 1-3 seconds. The students wore pedometer for four days and took the questionnaire on the fifth and final day of data collection. During the questionnaire administration, each researcher was able to answer any questions related to the questionnaire and reminded students they would not be punished if they no longer wished to participate in the study. The questionnaire was given in PE to each participating student during the fifth day of 
data collection. The questionnaire was administered in the beginning of each PE lesson. It was estimated to take approximately twenty minutes.

Data collection took place four or five school days at each school. Each participant was given a numbered pedometer at the beginning of the study. The participants wore pedometers (Walk4Life, LS 2500, Plainfield, IL) for four consecutive PE periods. During days one through four, the researcher handed out pedometers at the beginning of the class period and then collected the pedometers at the end of the class period. The researcher recorded the final step count and activity time at the end of the PE class onto an Excel sheet with the corresponding participant number.

On the final day of data collection, the PMCSQ-2 and PACES questionnaires were administered to the participants at the beginning of their PE class. All student information was kept confidential, only allowing researchers to obtain any specific answers linking the student to their responses. The PMCSQ-2and PACES took approximately 15 minutes for the participants to complete on the final day of data collection.

\section{Description of Physical Education Lessons}

Similar activities were taught at Schools 1, 2, and 3, but they were constructed differently. Data collection at School 1 was scheduled to take place over two weeks in February. Due to a snow storm the data collection dates had to be extended into a third week. School 1 was on an A/B rotation, meaning that they saw their students every other day for one full year. There were three PE teachers participating from this school (two males, one female). Every two weeks one teacher would rotate out of PE and start health. Due to the snow storm, some PA data were lost and not made up because one of the PE 
teachers had to rotate into health and the health teacher had to rotate into PE. Pedometer data were still collected for four days, but any participating student who was absent during those four days was not able to make up the missed data because of rotating into health. The teachers at this school used direct instruction during class.

School 1 followed the Dynamic Physical Education (DPE) format of a four part lesson. The students had 25 minutes of activity time after designating ten minutes for dressing out and five minutes of free play at the beginning of each class. Only select classes had free time, as three classes initially met in the gymnasium with one of those classes heading to the health room after the bell rang. The free time at the beginning of class was meant for the health students to be active while PE students were dressing out. Pedometers were not worn during free time because it was not a consistent measure of time, and not every participating student was offered free play during that time.

While observing the lessons at School 1, it was apparent that the DPE lessons being taught offered the opportunity to accumulate a large number of steps. Each lesson was taught twice, once for A day and once for B day. There were nine periods at School 1, and period 3 was a choice period following the same lesson plan, but the students were allowed to choose which skill they wanted to work on. A block plan has outlined the unit plan taught over the ten day data collection period at School 1. Missing PA and survey data for School 1 included thirty seven participants.

\begin{tabular}{|l|l|c|c|c|l|}
\hline & Day 1/Day 2 & Day 3/ Day 4 & Day 5/ Day 6 & Day 7/ Day 8 & Day 9/Day 10 \\
\hline Intro & Sharks and Minnows & Freeze Tag & Flag Grab & Train Tag & Poly Spot Fitness \\
\hline
\end{tabular}




\begin{tabular}{|c|c|c|c|c|c|}
\hline Fitness & Jump, Jog, Abs & Scavenger Hunt & Sports Cards & Racetrack & Poly Spot Fitness \\
& & & & Fitness & \\
\hline Skill & Volleyball/Basketball & Volleyball/Basketball & Volleyball/Basketball & Volleyball/ & Volleyball/Basketball \\
& & & & & Game \\
\hline Game & None & None & None & Skills Test & \\
& & & & Volleyball/Bask & Volleyball/Basketball \\
& & & & Game & Game \\
\hline
\end{tabular}

School 2 had one male PE teacher and an entire gym. The students would meet for nine weeks and then rotate into another elective if they did not get placed in PE again. This school had a Chinese Festival and two $8^{\text {th }}$ grade field trips during the data collection schedule. The $8^{\text {th }}$ grade students rotated to another exploratory for the new nine week period without making up any of the lost data. Thus, four days of PA data collection occurred with the $6^{\text {th }}$ and $7^{\text {th }}$ grade students at this school, while only three days were acquired with the $8^{\text {th }}$ grade students. Vincent and Pangrazi (2002) reported three to four days of data collection were sufficient to determine habitual activity levels; thus, these participants' data were maintained for data analysis. The teacher at School 2 used direct instruction during his class.

Data collection at School 2 also took place over a two week period, but was collected consistently over five days during the second week. This school was not on an 
A/B rotation, so the students met every day. The reason for only collecting data during the second week was because of one snow storm causing data collection to run into the first two days of data collection at School 2. The second reason was because of a Chinese Festival that would take place in the gym for the entire day. School 2 did not follow DPE, but the participating teacher did teach volleyball to the $7^{\text {th }}$ grade students. The $6^{\text {th }}$ grade students were in a track and field unit, and the $8^{\text {th }}$ grade students were finishing a fitness unit at the beginning of the week and started their track and field unit at the end of the week. During Maroon days, the class periods were 45 minutes long, but pedometers were only used for 30 minutes of the class. Students had a total of 14 minutes to dress out taking away from the whole 45 minutes. On regularly scheduled days, the classes were 55 minutes, and pedometers were used for 40 minutes.

\begin{tabular}{|c|c|c|c|c|c|}
\hline & Day 1 & Day 2 & Day 3 & Day 4 & Day 5 \\
\hline Warm-Up & $\begin{array}{l}\text { 1-2 laps } \\
\text { around gym, } \\
\text { Stretching in } \\
\text { large circle }\end{array}$ & $\begin{array}{l}\text { 1-2 laps } \\
\text { around gym, } \\
\text { Stretching in } \\
\text { large circle }\end{array}$ & $\begin{array}{l}\text { 1-2 laps } \\
\text { around gym, } \\
\text { Stretching in } \\
\text { large circle }\end{array}$ & $\begin{array}{l}\text { 1-2 laps } \\
\text { around gym, } \\
\text { Stretching in } \\
\text { large circle }\end{array}$ & $\begin{array}{l}\text { 1-2 laps } \\
\text { around gym, } \\
\text { Stretching in } \\
\text { large circle }\end{array}$ \\
\hline Activity & $\begin{array}{l}\text { 6- Track Unit } \\
* 5 \text { minute run } \\
\text { test } \\
\text { 7- Volleyball } \\
\text { *Circle chest } \\
\text { passing } \\
\text { 8- Fitness Unit }\end{array}$ & $\begin{array}{l}\text { Choice Day } \\
\text { Options: } \\
\text { 1. Basketball } \\
\text { 2. Soccer } \\
\text { 3. Volleyball } \\
\text { 4. Stationary } \\
\text { Bikes }\end{array}$ & $\begin{array}{l}\text { 6- Net Games } \\
\text { Stations: } \\
\text { Ping-Pong, } \\
\text { Pickle ball, } \\
\text { Badminton, } 4 \\
\text { Square } \\
\text { 7-Volleyball } \\
\text { *2 Games }\end{array}$ & $\begin{array}{l}\text { 6- Net Games } \\
\text { Stations: } \\
\text { Ping-Pong, } \\
\text { Pickle ball, } \\
\text { Badminton, } 4 \\
\text { Square } \\
\text { 7- Volleyball } \\
\text { *2 Games }\end{array}$ & $\begin{array}{l}\text { 6- Net Games } \\
\text { Stations: } \\
\text { Ping-Pong, } \\
\text { Pickle ball, } \\
\text { Badminton, } 4 \\
\text { Square } \\
\text { 7- Volleyball } \\
* 2 \text { Games }\end{array}$ \\
\hline
\end{tabular}




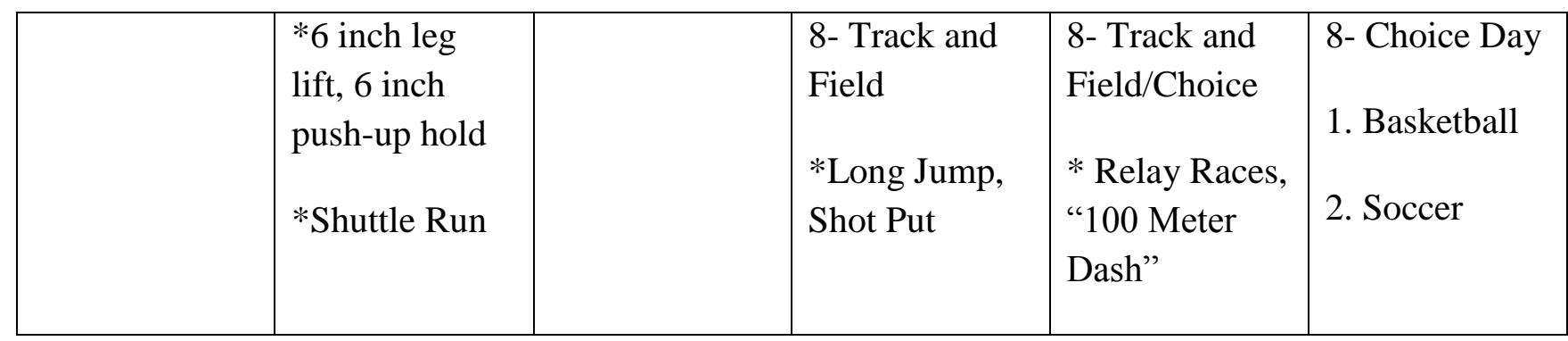

Every class started by running laps and would then stretch as a group. Following the warm-up, they started the skills they were going to learn during that lesson. The $7^{\text {th }}$ grade volleyball unit was not consistent with developmentally appropriate practices, but the students appeared to enjoy the activities which included passing and catching drills. During the first day of volleyball, the students stood around in groups of five to seven and tossed the volleyball back and forth with each other for seven to ten minutes. After they mastered tossing one volleyball, the teacher would add another volleyball, totaling up to five volleyballs. The students completed the end of the class with choice time. The $6^{\text {th }}$ grade track unit consisted of warm-up laps, stretching, and a shuttle run. After completing the shuttle run, the class had choice time. The $8^{\text {th }}$ grade fitness test consisted of a push-up hold, leg lift hold, and the shuttle run. They were encouraged to beat personal fitness scores from earlier in the year. Following the fitness test the students had choice time.

Day 2 of data collection was a choice day with four stations. The stations were Ping-Pong, basketball, soccer, volleyball. Day 3 continued the volleyball unit plan for the $7^{\text {th }}$ graders, track and field for the $8^{\text {th }}$ graders, and the $6^{\text {th }}$ graders were allowed the choice of badminton, pickle ball, Ping-Pong, or 4-square. Day 4 consisted of choice for the $6^{\text {th }}$ grade, volleyball for $7^{\text {th }}$ grade, and track and field for the $8^{\text {th }}$ grade. 
During the Day 5 of data collection, the surveys were given out at the beginning of the PE lesson. All of the participating students were seated on the stage and were told about the survey. Students were asked not to talk, but to raise their hand if they had a question or comment about the survey. Missing PA data for School 2 included thirty eight participants.

School 3 had one male PE teacher and an entire gym. He used direct instruction during his classes. Due to rotating out of the gym and into health, only three days of PA were acquired for the participants at this school, and any students who were absent during that time were not able to make up the missed data. Missing PA data for School 3 included nine participants.

School 3 was in between the structure of School 1 and the looseness of School 2. The lessons were 45 minutes long and the students did not dress out. School 3 was beginning a handball unit with all of their students. There was one teacher in the gym with average sized classes of 28 . The teacher began with walking laps and stretching and then moved onto noodle tag. From there, the teacher practiced throwing, catching, and passing skills used in a handball game. Following the skills, the teacher had the students play a 15 to 20 minute game of handball. The teacher picked the teams and it was girls vs. girls and boys vs. boys. At the end of class the students would walk cool down laps. Due to snow days and a switching of schedules from PE to health, students in School 3 were only able to wear pedometers for three school days, which is acceptable according to Vincent and Pangrazi (2002). 


\begin{tabular}{|l|l|l|l|l|}
\hline & Day 1 & Day 2 & Day 3 & Day 4 \\
\hline Warm-Up & $\begin{array}{l}\text { Walk laps, } \\
\text { Stretching } \\
\text { (Jumping } \\
\text { jacks, plank, } \\
\text { push-ups, sit- } \\
\text { ups), Noodle } \\
\text { tag }\end{array}$ & $\begin{array}{l}\text { Walk laps, } \\
\text { Stretching } \\
\text { (Jumping } \\
\text { jacks, plank, } \\
\text { push-ups, sit- } \\
\text { ups), Noodle } \\
\text { tag, 4 Corner } \\
\text { Fitness }\end{array}$ & $\begin{array}{l}\text { Walk laps, } \\
\text { Pac-Man Tag, } \\
\text { 4 Corner } \\
\text { Fitness }\end{array}$ & Health Room \\
& $\begin{array}{l}\text { Handball- } \\
\text { Tossing and } \\
\text { catching }\end{array}$ & None & $\begin{array}{l}\text { Handball- 2 } \\
\text { Minute Review }\end{array}$ & Health Room \\
\hline Activity/Skill & Chest & - 3 steps, 3 & \\
2. Overhead & passes & \\
\hline Game & Boys vs. Boys & Boys vs. Boys & Boys vs. Boys & Health Room \\
& Girls vs. Girls & Girls vs. Girls & Girls vs. Girls & \\
\hline Cool-Down & Walk Laps & Walk Laps & Walk Laps & Health Room \\
\hline
\end{tabular}

\section{Data Analysis}

Student enjoyment and PA time were considered dependent variables, while the student perceived motivational climate, grade, gender, and ethnicity were considered independent variables. SPSS 22.0 statistical package was used to analyze the participants' responses to the PMCSQ-2 and PACES. The pedometer activity time and total steps per minute were entered into Excel.

Basic descriptive statistics were used to analyze current PA levels (percentage of time active during PE), enjoyment, and perceived motivational climate. Percentage of 
time active was calculated by total time active divided by total class time. Correlations were conducted among all study variables [results will show a correlation matrix] to determine if relationships existed.

Four regression analyses were run to determine relationships among variables. The first regression analysis was performed to identify significant relationships between the mastery and performance climates with student enjoyment, while controlling for school, gender, grade, and ethnicity. The second regression analysis was used to identify significant relationships between the mastery and performance climates with PA, while controlling for school, gender, grade, and ethnicity. The third regression analysis was used to identify significant relationships between effort/improvement, cooperative learning, important role, punishment for mistake, unequal recognition, and team rivalry with enjoyment while controlling for school, gender, grade, and ethnicity. The fourth regression analysis was used to identify significant relationships between effort/improvement, cooperative learning, important role, punishment for mistake, unequal recognition, and team rivalry with PA, while controlling for school, gender, grade, and ethnicity. If any predictor variables in the regression analysis were reported as multicollinearity, or any variables in a multiple regression were highly correlated, only one was analyzed to offset calculations regarding individual predictors.

\section{Results}

There were nine research questions for this study. The research questions are listed below and contain a summary of the results question by question.

1. What are current physical activity levels of students in middle school physical education? 
2. What are current enjoyment levels of students in middle school physical education?

3. What is the overall student perceived motivational climate in middle school physical education?

4. What are the correlations between mastery climate, performance climate, enjoyment, physical activity, effort/improvement, cooperative learning, important role, punishment for mistake, unequal recognition, and team rivalry?

5. Do physical activity, enjoyment, and motivational climate differ by gender, grade, and ethnicity?

6. What is the relationship between the mastery climate with enjoyment, while controlling for school, gender, grade, and ethnicity? What is the relationship between the performance climate with enjoyment, while controlling for school, gender, grade, and ethnicity?

7. What is the relationship between the mastery climate with physical activity, while controlling for school, gender, grade, and ethnicity? What is the relationship between the performance climate with physical activity, while controlling for school, gender, grade, and ethnicity?

8. What is the relationship between effort/improvement with enjoyment, while controlling for school, gender, grade, and ethnicity? What is the relationship between cooperative learning with enjoyment, while controlling for school, gender, grade, and ethnicity? What is the relationship between important role with enjoyment, while controlling for school, gender, grade, and ethnicity? What is the relationship between punishment for mistake with enjoyment, while controlling 
for school, gender, grade, and ethnicity? What is the relationship between unequal recognition with enjoyment, while controlling for school, gender, grade, and ethnicity? What is the relationship between team rivalry with enjoyment, while controlling for school, gender, grade, and ethnicity?

9. What is the relationship between effort/improvement with physical activity, while controlling for school, gender, grade, and ethnicity? What is the relationship between cooperative learning with physical activity, while controlling for school, gender, grade, and ethnicity? What is the relationship between important role with physical activity, while controlling for school, gender, grade, and ethnicity? What is the relationship between punishment for mistake with physical activity, while controlling for school, gender, grade, and ethnicity? What is the relationship between unequal recognition with physical activity, while controlling for school, gender, grade, and ethnicity? What is the relationship between team rivalry with physical activity, while controlling for school, gender, grade, and ethnicity? When examining current PA levels in middle school PE, it was found that on average, students from all three schools combined were active $52.10 \%$ of the time while in PE. Participants from School 1 were active $56.76 \%$ time active, participants from School 2 were active $39.63 \%$ of the time, and participants from School 3 were active $50.07 \%$ of the time.

Enjoyment levels were fairly high among participants in all three schools. On average, students from all three schools averaged a combined enjoyment level of 4.05 on a 5 point Likert scale. School 1 averaged 4.14 on a 5 point Likert scale, School 2 averaged 4.09, and School 3 averaged 3.58. 
Overall, students perceived a mastery climate more than a performance climate $\left(M_{m c}=3.78, M_{p c}=2.2\right)$. School 1 perceived a mastery climate more than a performance climate $\left(M_{m c}=3.75, M_{p c}=2.15\right)$. School 2 had the highest levels of a perceived mastery climate versus a performance climate $\left(\mathrm{M}_{\mathrm{mc}}=4.03, \mathrm{M}_{\mathrm{pc}}=2.22\right)$. School 3 perceived a mastery climate the least but still more so than a performance climate $\left(\mathrm{M}_{\mathrm{mc}}=3.48\right.$, $\left.\mathrm{M}_{\mathrm{pc}}=2.38\right)$.

The combined scores by gender suggest males perceive a mastery climate $(\mathrm{M}=3.82, \mathrm{SD}=.71)$ and a performance climate $(\mathrm{M}=2.25, \mathrm{SD}=.71)$ more than females $\left(\mathrm{M}_{\mathrm{mc}}=3.79, \mathrm{SD}=.69, \mathrm{M}_{\mathrm{pc}}=2.1, \mathrm{SD}=.65\right) .6^{\text {th }}$ grade perceived the highest mastery $(\mathrm{M}=3.94$, $\mathrm{SD}=.73)$ and performance climate $(\mathrm{M}=2.25, \mathrm{SD}=.74) .7^{\text {th }}$ grade perceived a mastery climate (M=3.74, SD.63) overall but did not have the second highest perception of a performance climate $(\mathrm{M}=2.08, \mathrm{SD}=.7) .8^{\text {th }}$ grade had the lowest perception of a mastery climate $(\mathrm{M}=3.69, \mathrm{SD}=.69)$ but the second highest perception of a performance climate $(\mathrm{M}=2.19, \mathrm{SD}=.56)$. Asian students perceived a mastery climate the least $(\mathrm{M}=3.39$, $\mathrm{SD}=.67)$ while Hispanic students perceived it the most $(\mathrm{M}=3.96, \mathrm{SD}=.53)$. The ethnic category Other perceived the performance climate the most $(\mathrm{M}=2.36, \mathrm{SD}=.78)$ while Asian students perceived it the least $(\mathrm{M}=2.11, \mathrm{SD}=.57)$.

The correlations between mastery climate, performance climate, enjoyment, physical activity, effort/improvement, cooperative learning, important role, punishment for mistake, unequal recognition, and team rivalry are presented in Table 2. Mastery climate had a strong positive relationship with effort and improvement, important role, and cooperative learning. Average enjoyment had a strong positive relationship with mastery climate, effort and improvement, and a moderate relationship with important 
role, and cooperative learning. Performance climate had a strong positive relationship with punishment for mistake, unequal recognition, and intra class rivalry.

Physical activity, enjoyment, and motivational climate were found to be different by gender, grade, and ethnicity. Males (57\%) are more active than females (48\%); 7th grade was the most active (56\%) compared to 6th (48\%), and 8th (54\%); Hispanic students had the least percentage of time active during PE (45\%) compared to Other (51\%), Black (51\%), White (55\%), and Asian (60\%). See Tables 3, 4, and 5.

To assess the relationship between average enjoyment and time active with mastery and performance scores, multiple regressions were conducted, controlling for school, gender, grade, and ethnicity. $P$ values $<.05$ were considered statistically significant. Statistically significant relationships were found between both performance and mastery scores with enjoyment. The relationship for the performance score was negative while the mastery relationship was positive. See Table 1.

Regression effects reveal there was a significant positive relationship between a perceived mastery climate and enjoyment $\mathrm{p}<.001,\left[F(8,281)=22.97, p<.05, R^{2}=0.40\right.$, $R^{2}$ Adjusted $\left.=.38\right]$. Also, a significant negative relationship was found between a perceived performance climate and enjoyment, $\mathrm{p}<.000239[\mathrm{t}(281=-3.722), F(8,281)=$ $7.379, p<.05, R^{2}=0.17, R^{2}$ Adjusted $\left.=.15\right]$.

There was not a significant relationship between the mastery climate and physical activity, $\mathrm{p}<0.398\left[F(8,279)=8.684, p>.05, R^{2}=0.20, R^{2}\right.$ Adjusted $\left.=.18\right]$, or between the performance climate and physical activity, $\mathrm{p}<.12\left[F(8,279)=8.483, p>.05, R^{2}=0.20\right.$, $R^{2}$ Adjusted $\left.=.17\right]$. 
When assessing the mastery climate subcategories using six multiple regression analyses, there was a significant positive relationship between effort/improvement and enjoyment, $\mathrm{p}<.0001\left[F(8,281)=22.97, p<.05, R^{2}=0.40, R^{2}\right.$ Adjusted $\left.=.38\right]$, cooperative learning and enjoyment, $\mathrm{p}<.0001\left[F(8,281)=14.58, p<.05, R^{2}=0.29, R^{2}\right.$ Adjusted $=$ $.27]$, and important role and enjoyment, $\mathrm{p}<.0001\left[F(8,281)=15.36, p<.05, R^{2}=0.30\right.$, $R^{2}$ Adjusted $\left.=.28\right]$. On the other hand, there was a significant negative relationship between punishment for mistake and enjoyment, $\mathrm{p}<.011\left[F(8,281)=6.33, p<.05, R^{2}=\right.$ $0.15, R^{2}$ Adjusted $\left.=.13\right]$, unequal recognition and enjoyment, $\mathrm{p}<.0001[F(8,281)=8.697$, $p<.05, R^{2}=0.20, R^{2}$ Adjusted $\left.=.18\right]$, and team rivalry and enjoyment $[F(8,281)=5.385$, $p>.05, R^{2}=0.13, R^{2}$ Adjusted $\left.=.11\right]$.

In sum, the results conclude there was no significant relationship between effort/improvement and physical activity $\left[F(8,279)=8.687, p>.05, R^{2}=0.20\right.$, $R^{2}$ Adjusted $\left.=.18\right]$, cooperative learning and physical activity $[F(8,279)=5.385, p>.05$, $R^{2}=0.19, R^{2}$ Adjusted $\left.=.17\right]$, important role and physical activity $[F(8,279)=8.831, p>$ $.05, R^{2}=0.20, R^{2}$ Adjusted $\left.=.18\right]$, punishment for mistake and physical activity $[F(8,279)$ $=8.54, p>.05, R^{2}=0.20, R^{2}$ Adjusted $\left.=.17\right]$, and team rivalry and physical activity $[F(8$, 279) $=8.464, p>.05, R^{2}=0.19, R^{2}$ Adjusted $\left.=.17\right]$. There was a significant positive relationship between unequal recognition and physical activity, $\mathrm{p}<.001[F(8,279)=$ $5.385, p<.05, R^{2}=0.20, R^{2}$ Adjusted $\left.=.18\right]$. 


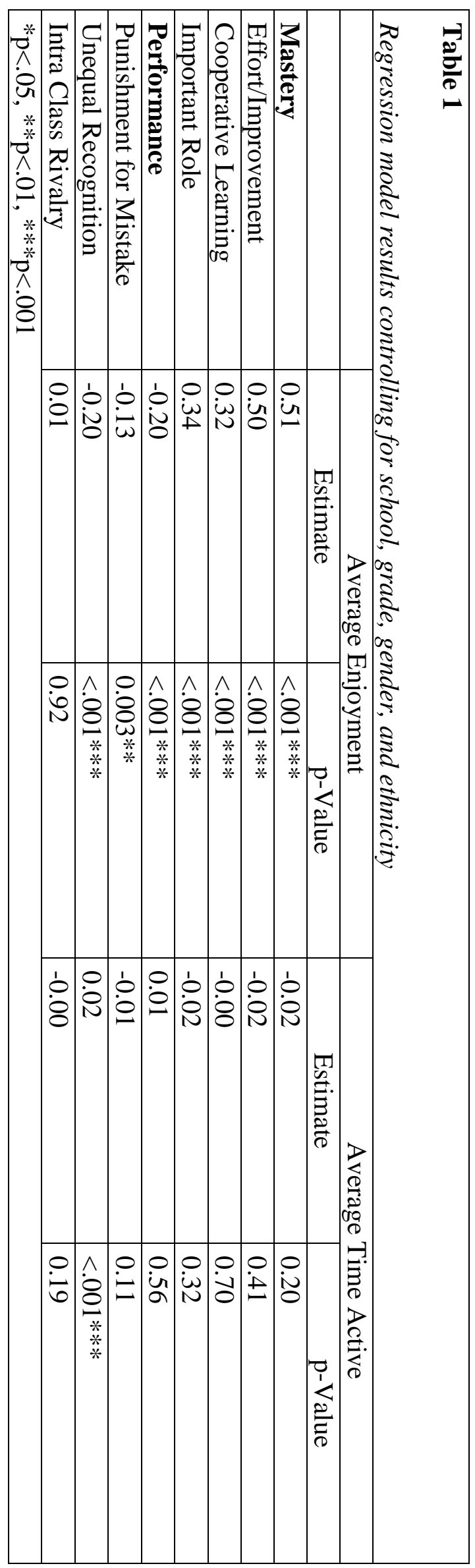




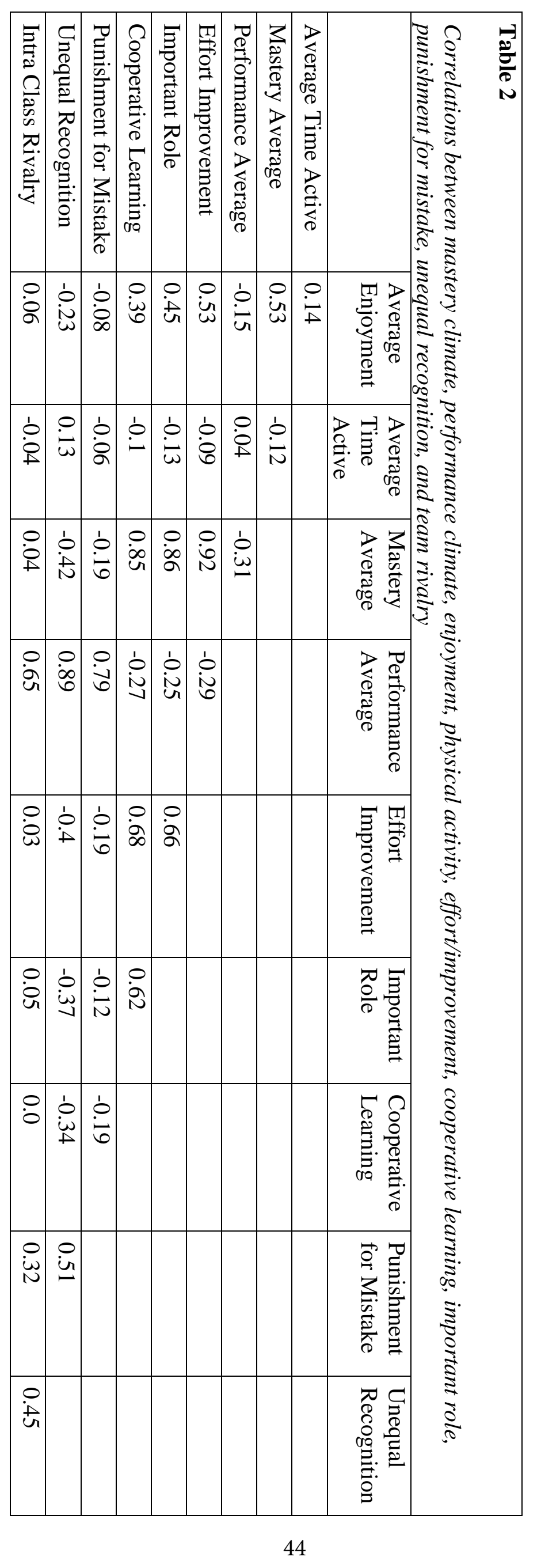




\begin{tabular}{|c|c|c|c|c|c|c|}
\hline$\infty$ & $\checkmark$ & $a$ & & $\sum_{[}^{\Omega}$ & $\frac{c}{3}$ & $\frac{\overrightarrow{0}}{\tilde{\omega}}$ \\
\hline $\begin{array}{l}w \\
w \\
w \\
w\end{array}$ & $\stackrel{+}{-}$ & $\stackrel{+}{\dot{v}}$ & 3 &  & i & \\
\hline$\stackrel{\circ}{-a}$ & $\begin{array}{l}0 \\
0\end{array}$ & $\begin{array}{l}0 \\
\dot{\alpha}\end{array}$ & $\stackrel{++}{\Xi}$ & 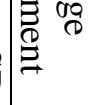 & B & \\
\hline $\begin{array}{l}0 \\
\dot{u} \\
\perp\end{array}$ & $\begin{array}{l}0 \\
\dot{y}_{1}\end{array}$ & $\begin{array}{l}0 \\
+\infty \\
\infty\end{array}$ & 3 & 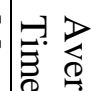 & 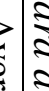 & \\
\hline$\stackrel{\circ}{a}$ & $\stackrel{0}{a}$ & $\stackrel{\circ}{a}$ & $\stackrel{++}{\Xi}$ & $\underset{\infty}{\stackrel{\infty}{\rightleftharpoons}}$ & § & \\
\hline$\dot{\omega}$ & $\stackrel{\omega}{\vec{\perp}}$ & $\begin{array}{l}\omega \\
\dot{\phi}\end{array}$ & 3 & 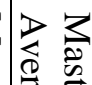 & & \\
\hline 잉 & o. & $\stackrel{\circ}{\omega}$ & $\stackrel{+1}{\Xi}$ & 80 & & \\
\hline$\stackrel{N}{*}$ & $\begin{array}{l}N \\
\stackrel{\infty}{\infty}\end{array}$ & $\begin{array}{l}N \\
ن \\
\sim\end{array}$ & 3 & $\mid \begin{array}{ll}\infty & 0 \\
\Omega & 0\end{array}$ & & \\
\hline 임 & $\stackrel{\ominus}{-}$ & $\stackrel{\circ}{+}$ & $\stackrel{+1}{\Xi}$ & $\mid \begin{array}{ll}\infty \\
\infty \\
0 \\
0\end{array}$ & & \\
\hline $\begin{array}{l}\omega \\
\infty \\
+\end{array}$ & $\begin{array}{l}w \\
\dot{\sigma} \\
N\end{array}$ & $\stackrel{\nabla}{=}$ & 3 & $\underset{8}{\stackrel{9}{0}}$ & & \\
\hline$\stackrel{\ominus}{\forall}$ & $\begin{array}{l}\dot{a} \\
\dot{\phi}\end{array}$ & $\stackrel{0}{\stackrel{0}{\omega}}$ & $\stackrel{+}{\Theta}$ & 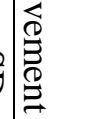 & & \\
\hline $\begin{array}{l}w \\
\dot{a} \\
a\end{array}$ & $\begin{array}{l}w \\
\dot{v} \\
y\end{array}$ & $\stackrel{\omega}{\ddot{A}}$ & $\stackrel{+1}{\Xi} 3$ & 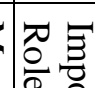 & & \\
\hline $\begin{array}{l}0 \\
\dot{\infty} \\
+\end{array}$ & $\begin{array}{l}0 \\
\dot{\infty} \\
\infty\end{array}$ & $\begin{array}{l}0 \\
\dot{\infty} \\
0\end{array}$ & & $\overrightarrow{\vec{\Xi}}$ & & \\
\hline $\begin{array}{l}\omega \\
\dot{g}\end{array}$ & $\begin{array}{l}w \\
\dot{w} \\
\mathbf{b}\end{array}$ & $\begin{array}{l}w \\
\infty \\
w \\
w\end{array}$ & 3 & $\mid$\begin{tabular}{ll}
$\Gamma$ & 8 \\
\hdashline & 8 \\
\hdashline & 8
\end{tabular} & & \\
\hline $\begin{array}{l}0 \\
\dot{\infty} \\
\alpha\end{array}$ & $\begin{array}{l}0 \\
\dot{0} \\
0\end{array}$ & $\begin{array}{l}0 \\
\dot{0}\end{array}$ & $\stackrel{H}{\Xi}$ & ${ }^{10}$ & & \\
\hline $\begin{array}{l}N \\
\stackrel{N}{O}\end{array}$ & $\begin{array}{r}\dot{\infty} \\
N\end{array}$ & $\begin{array}{l}N \\
\dot{\infty}\end{array}$ & 3 & 空 & & \\
\hline$\stackrel{\circ}{\sim}$ & $\stackrel{0}{N}$ & $\begin{array}{l}. \\
\dot{\infty}\end{array}$ & $\stackrel{+}{\Delta}$ & i) & & \\
\hline$\stackrel{N}{\stackrel{\omega}{\omega}}$ & $\stackrel{N}{P}$ & $\stackrel{N}{\vec{a}}$ & 3 & $\mid$\begin{tabular}{ll}
$\pi$ & \multicolumn{1}{|c}{} \\
0 & $\overline{0}$ \\
$\delta$ & 0
\end{tabular} & & \\
\hline $\begin{array}{l}0 \\
\infty \\
\omega\end{array}$ & \begin{tabular}{c}
0 \\
$\infty$ \\
\hdashline \\
$\forall$
\end{tabular} & $\begin{array}{l}0 \\
\dot{8}\end{array}$ & $\stackrel{H}{\Xi}$ & 2 & & \\
\hline$\stackrel{N}{\grave{N}}$ & $\begin{array}{l}N \\
\stackrel{N}{ \pm}\end{array}$ & $\stackrel{N}{\stackrel{N}{O}}$ & 3 & 希 & & \\
\hline $\begin{array}{l}0 \\
\text { io }\end{array}$ & $\begin{array}{l}0 \\
\text { 이 }\end{array}$ & 웅 & $\stackrel{+1}{\Omega}$ & b) & & \\
\hline
\end{tabular}




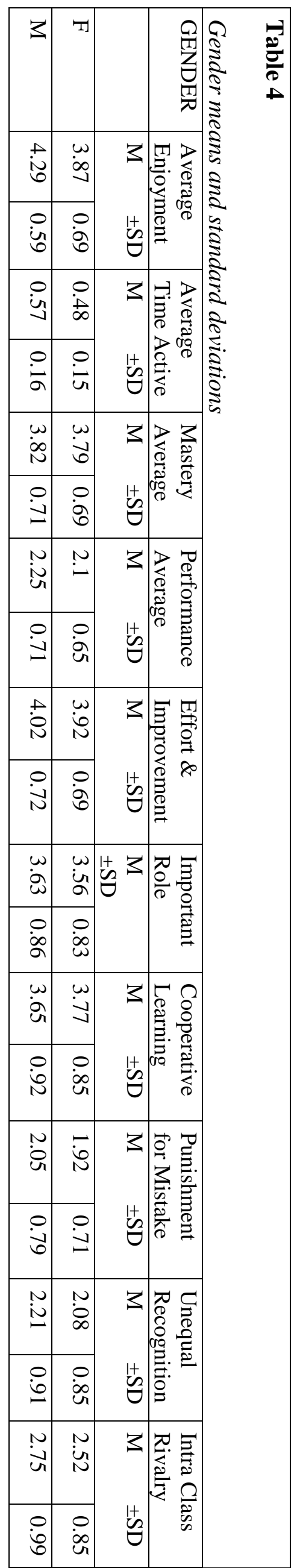




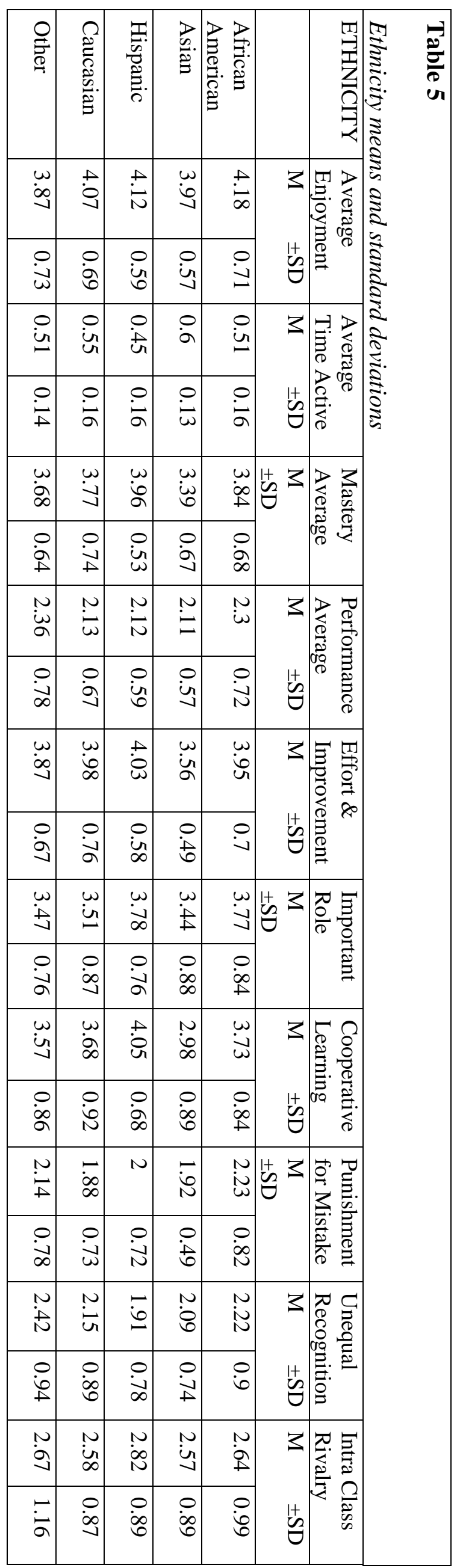




\section{Discussion}

The purpose of this study was to determine if student perceived motivational climate predicted enjoyment and PA levels while controlling for school, gender, grade, and ethnicity in middle school PE. It was found that a mastery oriented climate predicted enjoyment, but there were no significant results to predict PA levels in middle school students. In addition to the findings, it should be noted that missing data from $8^{\text {th }}$ grade could have influenced outcomes.

\section{Physical Activity Levels and Enjoyment Levels in Physical Education}

On average, participants were active $52.10 \%$ of the time while in PE. This was a positive, yet unexpected finding, as other studies such as Fairclough and Stratton (2005) have found that on average students are active between $27 \%$ and $47 \%$ of time in PE. Nader (2003) demonstrated through rigorous direct observation methods, specifically SOFIT, that students spent $37 \%$ of class time above a moderate intensity level in PE. In the current study, males were active on average $57 \%$ of the class time and females were active on average $48 \%$ of class time. In a study on girls' activity levels and lesson contexts in middle school PE conducted by McKenzie and colleagues (2006), it was found that middle school girls were active $37.9 \%$ of PE time. As described briefly in the Methods, the teachers at School 1 utilized four-part lessons, which potentially improved the efficiency of the lesson, thus, increasing the average time active to $56.76 \%$. While beyond the scope of this study, it could be that the lessons in DPE, which are specifically designed to maximize activity and to be taught using strategies to maximize PA, coupled with teaching practices described in DPE, resulted in higher PA levels. All units at School 1 included a fitness portion for each lesson, which has been suggested by 
Fairclough and Stratton (2005) to have the highest MVPA levels (48\%). For the skill part of the lesson one teacher taught volleyball and the other taught basketball (i.e., team invasion). In the Fairclough study, these were indicated as having the second highest MVPA levels at $46 \%$. Thus, the units taught may have also impacted the higher than expected PA values of the students.

Enjoyment levels in middle school PE were fairly high overall. On average, students from all three schools averaged an enjoyment score of 4.05 on a 5 point Likert scale. Males enjoyed PE more than females $\left(\mathrm{M}_{\mathrm{m}}=4.29, \mathrm{M}_{\mathrm{f}}=3.87\right)$. With $45.5 \%$ of middle school students in Kentucky attending daily PE class, it is important to offer activities that students enjoy in hopes of decreasing the average obese rate of $17.6 \%$ (CDC, 2010).

One study by Barr-Anderson and colleagues (2008) aligns with these results. Their findings suggest 50\% of females agreed with the statement "I enjoy PE class a lot" while $27 \%$ agreed with the statement "I enjoy PE class a little." Their study also suggests that Black females enjoy PE more than White females. The ethnic breakdown of the current study is similar with Black students enjoying PE with an average score of 4.18, Hispanic students enjoying PE with an average of 4.12, Caucasian students enjoying PE with an average of 4.07, Asian students enjoying PE with an average score of 3.97, and Other students enjoying PE with an average of 3.87 out of a 5 point scale. One reason for the high enjoyment score could be a result of a well-structured PE program. The participating teachers were also in their position for multiple years and were very familiar with their students and the curriculum. It was noted anecdotally that the teachers demonstrated a number of qualities that could have enhanced enjoyment, such as knowing students' names, interacting with students fairly often throughout the lessons, 
avoiding elimination activities, and using teaching practices that allow all students equal opportunity to participate. Future implications for PE teachers could be to use an instrument such as the Physical Activity Preferences Profile for Youth. This instrument takes into account student preferences for activities taught in PE.

\section{Student Perceived Motivational Climate}

The majority of students perceived a mastery climate opposed to a performance climate $\left(M_{m c}=3.78, M_{p c}=2.2\right)$. Parish and Treasure (2003) discussed perceptions of a mastery-oriented motivational climate being positively related to PA behavior. A study conducted by Carr and Weigand (2008) revealed students with high mastery and high performance profiles had higher levels of intrinsic motivation, but other profiles such as a combined high mastery/low performance, low mastery/high performance, and low mastery/low performance also had higher levels of intrinsic motivation due to exposure of a perceived mastery climate.

In the current study, the combined scores by gender suggest males perceive a mastery climate $(\mathrm{M}=3.82, \mathrm{SD}=.71)$ and a performance climate $(\mathrm{M}=2.25, \mathrm{SD}=.71)$ more so than females $\left(\mathrm{M}_{\mathrm{mc}}=3.79, \mathrm{SD}=.69, \mathrm{M}_{\mathrm{pc}}=2.1, \mathrm{SD}=.65\right)$. Students in $6^{\text {th }}$ grade perceived the highest mastery $(\mathrm{M}=3.94, \mathrm{SD}=.73)$ and performance climate $(\mathrm{M}=2.25, \mathrm{SD}=.74)$. Those in $7^{\text {th }}$ grade perceived a mastery climate (M=3.74, SD.63) overall and had the lowest perception of a performance climate $(M=2.08, S D=.7)$. Those in $8^{\text {th }}$ grade had the lowest perception of a mastery climate $(\mathrm{M}=3.69, \mathrm{SD}=.69)$, but the second highest perception of a performance climate $(\mathrm{M}=2.19, \mathrm{SD}=.56)$. Asian students had the lowest perceived mastery climate $(\mathrm{M}=3.39, \mathrm{SD}=.67)$ while Hispanic students perceived it the most $(\mathrm{M}=3.96, \mathrm{SD}=.53)$. The $8^{\text {th }}$ grade students at $\mathrm{School} 3$ could have altered the 
perception they perceived during the questionnaire. One explanation could be the presence of the teacher being in the same room the questionnaire was being given. One way to prevent this in future studies is for the observer to use a coding tool such as Morgan and colleagues' (2005) TARGET coding for the analysis of teaching behaviors related to the motivational climate and to have the PE teacher step out of the room during the questionnaire part. The results suggest perceiving a mastery climate overall and perceiving a performance climate the least produced the highest PA levels. Students in $7^{\text {th }}$ grade were the most active while the males enjoyed PE more than the females in this grade. Based on the $7^{\text {th }}$ grade results, PE teachers should strive to create a mastery climate and continue to work on enjoyment levels in female students. The ethnic category Other perceived the performance climate the most $(\mathrm{M}=2.36, \mathrm{SD}=.78)$, while Asian students perceived it the least $(\mathrm{M}=2.11, \mathrm{SD}=.57)$. Asian participants were the most active in this study so, once again, PE teachers should try to create a mastery oriented climate while eliminating any perceptions of a performance climate. These findings support other studies in that a mastery climate is perceived by majority of the students regardless of gender, grade, or ethnicity, and that males enjoy PE more than females. This study has shown that trend is still occurring and that PE teachers need to be aware and proactive in how they emphasize structures in their classroom to increase enjoyment and PA levels.

\section{Associations between Variables}

The ten variables surveyed in this study were mastery climate, performance climate, enjoyment, physical activity, effort/improvement, cooperative learning, important role, punishment for mistake, unequal recognition, and team rivalry. There were a number of associations. Average enjoyment had a strong positive relationship 
with mastery climate, effort and improvement, and a moderate relationship with important role, and cooperative learning. In sum, this just means that the subcategories are highly related to the two higher order factors and enjoyment was higher when a mastery climate and its subcategories were perceived.

\section{Physical Activity, Enjoyment and Motivational Climate by Gender, Grade and}

\section{Ethnicity}

Physical activity, enjoyment, and motivational climate were found to be different by gender, grade, and ethnicity. Males $(\mathrm{M}=57 \%, \mathrm{SD}=16)$ were more active than females $(\mathrm{M}=48 \%, \mathrm{SD}=15) ; 7^{\text {th }}$ grade was the most active $(\mathrm{M}=56 \%, \mathrm{SD}=16)$ compared to $6^{\text {th }}(\mathrm{M}=48 \%, \mathrm{SD}=16)$, and $8^{\text {th }}(\mathrm{M}=54 \%, \mathrm{SD}=16)$. Hispanic students were the least active $(\mathrm{M}=45 \%, \mathrm{SD}=16)$ compared to Other $(\mathrm{M}=51 \%, \mathrm{SD}=14)$, Black $(\mathrm{M}=51 \%, \mathrm{SD}=16)$, White

$(\mathrm{M}=55 \%, \mathrm{SD}=16)$, and Asian $(\mathrm{M}=60 \%, \mathrm{SD}=13)$. This was an interesting finding because Asian students were the second to last on the enjoyment scale, but were the most active. This could be contributed to the low number of Asian participants in this study or that they are more disciplined and completed all of the tasks regardless of enjoyment.

The CDC (2005) suggests White males are the most active in school-based PA including PE, followed by Hispanic males, Black males, White females, Hispanic females and last Black females. In addition, the $\mathrm{CDC}$ reported when gender was combined, White was the most active followed by Hispanic and then Black ethnicities. The current findings differ slightly suggesting Asian students are the most active followed by White, Black, Other and then Hispanic. White students were very close to the Asian percentage of time active. The total Asian sample was very small compared to the White sample. 


\section{Relationship between Mastery Climate, Performance Climate and Enjoyment}

Statistically significant relationships were found between both mastery and performance scores with enjoyment. The performance relationship was negative while the mastery relationship was positive, meaning the higher the perceived performance climate score the lower the enjoyment. The findings regarding males having higher PA time is in line with studies conducted by Parish and Treasure (2003) and Fairclough and Stratton (2005). PE teachers should strive to create a mastery oriented climate to increase enjoyment for both genders, but specifically female students.

Even though this is in line with related literature, the choice of the units taught could have resulted in girls enjoying PE less. Treanor and colleagues (1998) completed a study comparing co-educational classes in the fall and same-gender classes in the spring. Males enjoyed PE significantly more and females decreased in enjoyment every year from $6^{\text {th }}$ to $8^{\text {th }}$ grade. In a similar study, Ronspies (2011) conducted one on one semistructured interviews with six students, three male and three female, in co-educational and single-gendered classes. Two out of the three girls preferred co-educational PE but the boys admitted to trying harder in single-gendered classes. Future research should examine if enjoyment differs by gender in single-gender versus co-educational PE classes. In summary, the findings suggest PE was enjoyed more by males than females, and perceiving a performance climate was negatively related to enjoyment. PE teachers should eliminate any emphasis they place on a performance climate structure to attempt to increase enjoyment in both genders, but specifically female students. 


\section{Relationship between Mastery Climate, Performance Climate and Physical Activity in Physical Education}

There was not a significant relationship between the mastery climate and PA or between the performance climate and PA during PE. One reason for the lack of a significant result may be a result brought up by Gran et al. (2013) stating the relationship between performance climate and PA is clouded and more investigation is needed to explore how the performance climate relates to PA outcomes. Parish and Treasure (2003) did not find a relationship between perceptions of a performance climate in PE and PA, but suggest perceptions of a mastery-oriented motivational climate to be positively related to PA behavior. PE teachers should continue to create a mastery oriented climate using TARGET structures, discussed previously, to increase practice opportunities and maximize activity time. Once again, the type of activity being taught could result in females being less engaged. Future research should focus on the type of activity being taught in single-gendered versus co-educational PE classes. An additional study could use an observation tool to assess performance and mastery climates and compare results to the questionnaire completed by participants. Morgan and colleagues' (2005) TARGET measure allows observers to systematically code the teaching behaviors that impact the students' perceptions of the motivational climate.

\section{Relationship between the Subcategories and Enjoyment}

There was a significant positive relationship between Effort/Improvement, Cooperative Learning, Important Role, and a significant negative relationship between Punishment for Mistake, Unequal Recognition, Intra Class Rivalry and enjoyment. Students enjoyed PE significantly more if the teacher stressed Effort/Improvement, or 
wanting students to try new skills, Cooperative Learning, or students helping each other learn, and Important Role, or discussing with students that learners at all levels are necessary to the success of the class, in class. Students enjoyed PE significantly less if the teacher stressed Punishment for Mistake, or emphasizing that only the best students can contribute to the class, Unequal Recognition, or the teacher having favorites, and Intra Class Rivalry, encouraging students to outplay other students. While teaching, PE teachers should focus on the learning process versus the product and positive feedback while eliminating punishments related to skill development, having star students, and encouraging competition between classmates.

\section{Relationship between the Subcategories and Physical Activity}

There was one significant relationships between Unequal Recognition and PA from all of the subcategories, Effort/Improvement, Cooperative Learning, Important Role, Punishment for Mistake, Unequal Recognition, Intra Class Rivalry. A significant relationship between unequal recognition and PA could identify students who felt they were the 'star' student may be more active. Even though there was only one significant relationships between the subcategories and PA, understanding all of the structures that are present while teaching are important for considering how to create a mastery oriented climate in PE class to attempt to increase PA levels and continuing to keep enjoyment levels high. The PE teacher could implement the TARGET structures into every day lesson plans to promote the creation of a mastery climate.

\section{Limitations}

In this research study, as with all research, limitations existed. First, PA levels depended highly upon the unit being taught during data collection as well as the 
management abilities of the teachers. For example, Fairclough and Stratton (2005) reported fitness and team invasion games resulted in the highest level of MVPA for PE students (46\%), while track and field only had 7.2\%-25.5\% MVPA. Graham and colleagues (2007) estimate dividing total class time into four categories. These four categories are coded as management, time getting water or taking attendance, instruction, pieces of information related to the skill or game being taught in class, waiting, time in long lines or waiting for other students to finish games or activities, and activity, time spent actively engaged in MVPA. Each class should spend an estimated 15\% of the total class in the management category, $30 \%$ in the instruction category, $5 \%$ in the waiting category and 50\% in the activity category (Graham, Holt/Hale, \& Parker, 2007). Second, gender preference towards units taught may have hindered activity levels and student enjoyment. Parish and Treasure (2003) and Fairclough and Stratton (2005) suggest boys are more active than girls in PE. This may have been due to the units being offered. Third, this is designed as a cross sectional study in which 3-4 days of PA data were collected. If this were a longitudinal study the researcher would be able to collect PA data over a longer period of time as well as track perceptions of the motivational climate from $6^{\text {th }}$ to $8^{\text {th }}$ grade to determine if trends existed.

\section{Conclusion}

Reaching the desired 50\% PA time in PE is essential in ensuring that students are reaching the recommended 60 minutes of PA per day. Based on the findings from the current study, it is also important to make PE enjoyable for all students in hopes of increasing PA. One way PE teachers can increase enjoyment is to create a mastery oriented climate in PE. TARGET offers strategies to help meet the PA recommendation 
set by Strong et al. (2005), describing that school-aged youth should participate in PA that is developmentally appropriate, enjoyable, and involves a variety of activities. Thus, one strategy for teachers to increase PA is by using the TARGET structures in their PE class. This study provides evidence that majority of students perceive a mastery climate, that males are more active and enjoyed PE more than females, and that Hispanic students were the least active. Based on these findings, one area to continue studying is the effect of the climate on gender and ethnicity.

While teaching middle school PE, teachers should focus on creating a mastery climate, teaching skills that their students enjoy, and reducing management time to increase opportunities for PA. PE teachers could benefit greatly from using a curriculum such as DPE which is based on a four part lesson. The four part lesson allows for each student to work on an introduction activity, fitness, skill, and game. This curriculum was shown to have the highest enjoyment and PA levels in this study while students still perceived a mastery oriented climate. More research is warranted to determine if varying curricula impact student enjoyment and PA in PE.

Although there was only one significant finding related to PA and the student perceived motivational climate, performance subcategory unequal recognition, this study provided some insight on where students are in relation to PA levels and perceived climates. All grade levels, both genders, and all ethnicities were more active when they perceived a higher mastery climate/lower performance climate. Additionally, this study found that students enjoy PE class more so when they perceived a mastery climate versus a performance climate. Higher enjoyment levels, which were present when a mastery climate was perceived, will hopefully lead to more PA and lifelong PA. When trying to 
establish a student to become physically active over a lifetime, the climate and enjoyment could be significant contributors.

\section{Further Research}

Based on the findings of this study, future studies could focus on collecting data in same-sex PE classes to uncover any differences in results. Females had lower enjoyment and PA levels throughout this study. Focusing on data collection in same-sex classes could yield more accurate information on females' perception of the motivational climate, enjoyment, and PA levels. An additional suggestion would be to conduct a longitudinal study. The decline in PA levels after fifth grade, especially in female students, is well documented, and research suggests that PA levels will continue to decline into adolescent and could even worsens into adulthood. If researchers could track student perceived motivational climate in addition to PA and enjoyment from $5^{\text {th }}$ to $9^{\text {th }}$ grade, there might be a better understanding of how to increase low PA and enjoyment levels.

An additional thought on the topic of future research would be to collect data from teachers at different levels in their career. For example, a beginning teacher might not be able to demonstrate effective teaching strategies for grouping and autonomy or even task differentiation leading students to perceive some aspects of a performance climate, but a teacher with five to seven years should be able to effectively implement the six TARGET structures into their program with the goal of creating a mastery climate.

If this study were to be repeated, one suggestion would be to add a TARGET observation tool. This would allow the researcher to compare student response to teacher actions. An additional thought would be to measure perceptions, PA levels, and 
enjoyment during different seasons of the year. Finally, the school with the highest PA and enjoyment levels followed a curriculum that is structured to increase PA and work on skill development. Observing different curriculums and what they emphasize could potentially give new feedback towards the climate, PA, and enjoyment levels. 
Appendix A

Perceived Motivational Climate in Sport Questionnaire-2 and Coding 
Please circle one: $6^{\text {th }}$ Grade $\quad 7^{\text {th }}$ Grade $\quad 8^{\text {th }}$ Grade

Please circle one: Male Female

Please circle one: African American, Asian, Hispanic, White Caucasian,

Other

Directions: Please think about how it has felt to participate in your PE class throughout this semester. What is it usually like in your class? Read the following statements carefully and respond the each in terms of how you view the typical atmosphere in your class. This is not a test, and you will not be graded on your answers.

In this Physical Education class...

\begin{tabular}{|c|c|c|c|c|c|}
\hline & $\begin{array}{l}\text { Strong } \\
\text { Strong } \\
\text { Agree }\end{array}$ & & & & \\
\hline $\begin{array}{l}\text { 1. The teacher wants students to try new } \\
\text { skills. }\end{array}$ & 1 & 2 & 3 & 4 & 5 \\
\hline $\begin{array}{l}\text { 2. The teacher gets mad when a student } \\
\text { makes a mistake. }\end{array}$ & 1 & 2 & 3 & 4 & 5 \\
\hline $\begin{array}{l}\text { 3. The teacher gives most of his or her } \\
\text { attention to the "stars." }\end{array}$ & 1 & 2 & 3 & 4 & 5 \\
\hline $\begin{array}{l}\text { 4. Each student contributes in some } \\
\text { important way. }\end{array}$ & 1 & 2 & 3 & 4 & 5 \\
\hline $\begin{array}{l}\text { 5. The teacher believes that all of the } \\
\text { students are crucial to the success of the } \\
\text { class. }\end{array}$ & 1 & 2 & 3 & 4 & 5 \\
\hline $\begin{array}{l}\text { 6. The teacher praises students only when } \\
\text { they out-perform other students. }\end{array}$ & 1 & 2 & 3 & 4 & 5 \\
\hline $\begin{array}{l}\text { 7. The teacher thinks only the best students } \\
\text { contribute to the success of the class. }\end{array}$ & 1 & 2 & 3 & 4 & 5 \\
\hline $\begin{array}{l}\text { 8. Students feel good when they try their } \\
\text { best. }\end{array}$ & 1 & 2 & 3 & 4 & 5 \\
\hline 9. Students are often sat out for mistakes. & 1 & 2 & 3 & 4 & 5 \\
\hline
\end{tabular}




\begin{tabular}{|c|c|c|c|c|c|}
\hline $\begin{array}{l}\text { 10. Students at all skill levels have an } \\
\text { important role in the class. }\end{array}$ & 1 & 2 & 3 & 4 & 5 \\
\hline 11. Students help each other learn. & 1 & 2 & 3 & 4 & 5 \\
\hline $\begin{array}{l}\text { 12. Students are encouraged to outplay the } \\
\text { other students. }\end{array}$ & 1 & 2 & 3 & 4 & 5 \\
\hline 13. The teacher has his or her own favorites. & 1 & 2 & 3 & 4 & 5 \\
\hline $\begin{array}{l}\text { 14. The teacher makes sure students } \\
\text { improve on skills they are not good at. }\end{array}$ & 1 & 2 & 3 & 4 & 5 \\
\hline $\begin{array}{l}\text { 15. The teacher yells at students for messing } \\
\text { up. }\end{array}$ & 1 & 2 & 3 & 4 & 5 \\
\hline $\begin{array}{l}\text { 16. Students feel successful when they } \\
\text { improve. }\end{array}$ & 1 & 2 & 3 & 4 & 5 \\
\hline $\begin{array}{l}\text { 17. Only the students with the best "stats" } \\
\text { get praise. }\end{array}$ & 1 & 2 & 3 & 4 & 5 \\
\hline $\begin{array}{l}\text { 18. Students are punished when they make } \\
\text { a mistake. }\end{array}$ & 1 & 2 & 3 & 4 & 5 \\
\hline 19. Each student has an important role. & 1 & 2 & 3 & 4 & 5 \\
\hline 20. Trying hard is rewarded. & 1 & 2 & 3 & 4 & 5 \\
\hline $\begin{array}{l}\text { 21. The teacher encourages students to help } \\
\text { each other. }\end{array}$ & 1 & 2 & 3 & 4 & 5 \\
\hline $\begin{array}{l}\text { 22. The teacher makes it clear who he or she } \\
\text { thinks the best students are. }\end{array}$ & 1 & 2 & 3 & 4 & 5 \\
\hline $\begin{array}{l}\text { 23. Students are "psyched" when they do } \\
\text { better than their classmates in a game. }\end{array}$ & 1 & 2 & 3 & 4 & 5 \\
\hline $\begin{array}{l}\text { 24. If you want to play in a game, you must } \\
\text { be one of the best students. }\end{array}$ & 1 & 2 & 3 & 4 & 5 \\
\hline $\begin{array}{l}\text { 25. The teacher emphasized always trying } \\
\text { your best. }\end{array}$ & 1 & 2 & 3 & 4 & 5 \\
\hline
\end{tabular}




\begin{tabular}{|c|c|c|c|c|c|}
\hline 26. Only the top students get noticed. & 1 & 2 & 3 & 4 & 5 \\
\hline 27. Students are afraid to make mistakes. & 1 & 2 & 3 & 4 & 5 \\
\hline $\begin{array}{l}\text { 28. Students are encouraged to work on } \\
\text { their weaknesses. }\end{array}$ & 1 & 2 & 3 & 4 & 5 \\
\hline $\begin{array}{l}\text { 29. The teacher favors some students more } \\
\text { than others. }\end{array}$ & 1 & 2 & 3 & 4 & 5 \\
\hline 30. The focus is to improve each class. & 1 & 2 & 3 & 4 & 5 \\
\hline 31. The students work well together. & 1 & 2 & 3 & 4 & 5 \\
\hline $\begin{array}{l}\text { 32. Each student feels as if they are an } \\
\text { important class member. }\end{array}$ & 1 & 2 & 3 & 4 & 5 \\
\hline $\begin{array}{l}\text { 33. The students help each other to get } \\
\text { better and excel. }\end{array}$ & 1 & 2 & 3 & 4 & 5 \\
\hline
\end{tabular}

\begin{tabular}{|l|l|l|}
\hline $\begin{array}{l}\text { Mastery or } \\
\text { Performance } \\
\text { Orientation }\end{array}$ & Subcategories & Question Numbers \\
\hline Mastery & Effort/Improvement & $1,8,14,16,20,25,28,30$ \\
\hline Mastery & Important Role & $4,5,10,19,32$ \\
\hline Mastery & Cooperative Learning & $11,21,31,33$ \\
\hline Performance & Punishment for Mistakes & $2,7,9,15,18,27$ \\
\hline Performance & Unequal Recognition & $3,13,17,22,24,26,29$ \\
\hline Performance & Intra-class Rivalry & $6,12,23$ \\
\hline
\end{tabular}


Appendix B

The Physical Activity in Children Enjoyment Scale (PACES) 
When I am physically active in PE:

1. I enjoy it

2. 1 feel bored

3. I dislike it

4. I find it pleasurable

Disagree

a lot

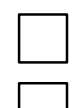

$\square$

$\square$

\section{Disagree \\ a lot}

5. It's no fun at all

6. It gives me energy

7. It makes me sad

8. It's very pleasant
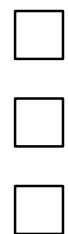

Disagree

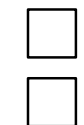

$\square$

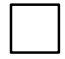

$\square$

Disagree
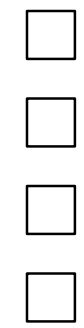

Disagree

a lot

Disagree



$\square$

$\square \quad \square$

$\square$

Disagree

a lot

Disagree

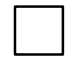

14. It gives me a strong feeling of success

15. It feels good

16. I feel as though I would rather be doing something else
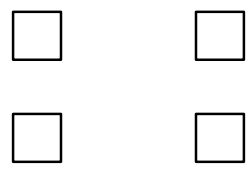

No opinion

Agree

Agree a

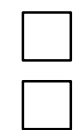

$\square$



No opinion


Agree

Agree a lot
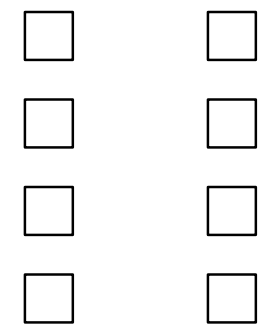

Agree

Agree a

lot opinion
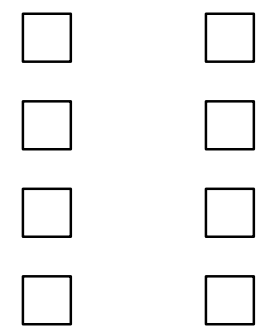

opinion

Agree

Agree a

lot
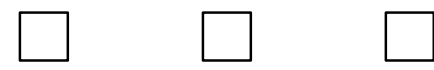
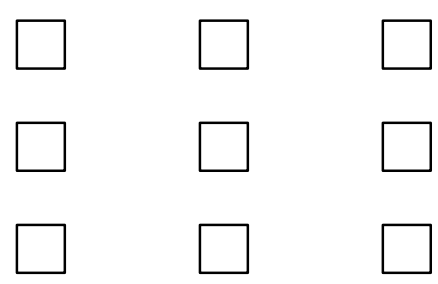
Appendix C

Parent Consent Form 


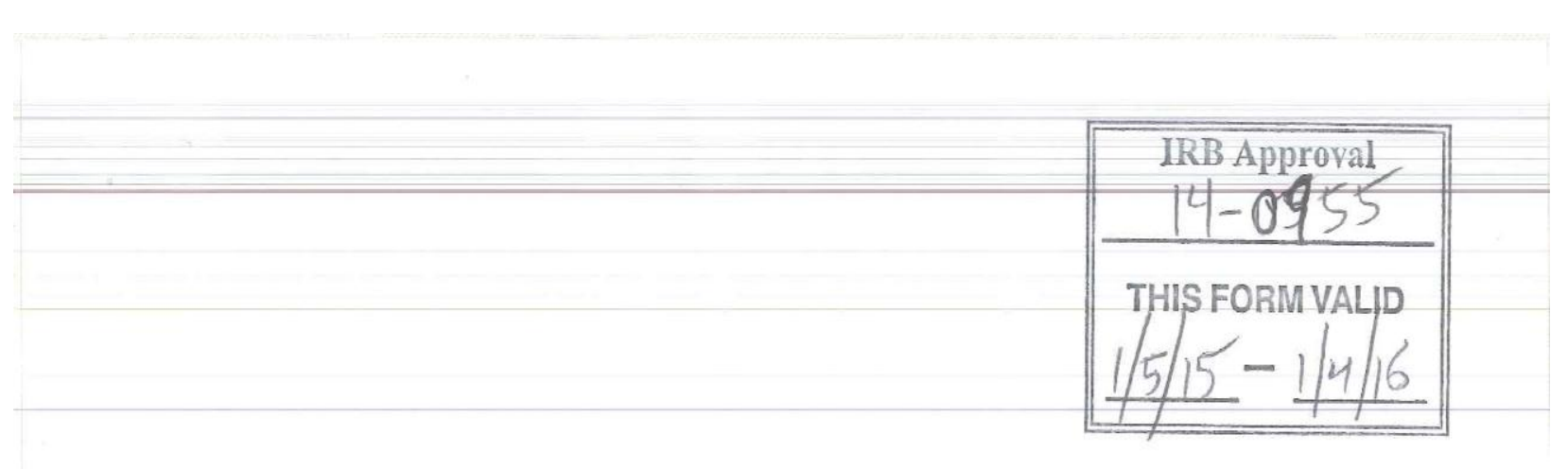

Consent to Participate in a Research Study

Student Perceived Motivational Climate, Student Enjoyment, and Physical Activity in Middle School Physical Education

WHY IS YOUR CHILD BEING INVITED TO TAKE PART IN THIS RESEARCH?

Your child is being invited to take part in a research study about children's perception of the motivational climate in Physical Education. Your child is being invited to take part in this research study because he/she attends school in Fayette County. If your child volunteers to take part in this study, he/she will be one of about 600 children to do so.

\section{WHO IS DOING THE STUDY?}

The person in charge of this study is Christine Johnson of University of Kentucky Department Kinesiology and Health Promotion. Christine Johnson is a third year PhD student with the University of Kentucky. Her faculty supervisor is Dr. Heather Erwin, Associate Professor in the Department Health Promotion. There may be other people on the research team assisting at different times during the study.

\section{WHAT IS THE PURPOSE OF THIS STUDY?}

The purpose of this study is to determine the relationship between students perceived motivational climate, enjoyment towards physical activity and physical activity levels in physical education.

Your child will participate in the study for one complete week in which he/she will wear a step counter and complete one questionnaire asking about their learning environment and their enjoyment towards physical activity.

\section{ARE THERE REASONS WHY YOUR CHILD SHOULD NOT TAKE PART IN THIS STUDY?}

There are no reasons why your child should not take part in this study.

\section{WHERE IS THE STUDY GOING TO TAKE PLACE AND HOW LONG WILL IT LAST?}

The research procedures will be conducted at three middle schools in Fayette County: Tates Creek Middle, Leestown Middle and Bryan Station Middle. Your child will participate in the study for five complete days. Pedometer collection and one questionnaire will be given during the last day of data collection in physical education. The questionnaire will only be given once at the end of the five days, and it will take approximately 20 minutes. The recording of their physical activity step count will take 1-2 minutes per day at the end of each lesson.

\section{WHAT WILL YOUR CHILD BE ASKED TO DO?}

Your child will be asked to do two things: (1) wear a pedometer on his/her waistband for five lessons in physical education, and (2) complete one questionnaire about the perceived motivational climate and enjoyment towards physical education. 
During five physical education classes in the 2014-2015 school year, your child will wear a pedometer on his/her waistband. The pedometer records your child's step counts and activity time. Researchers will record this information at the end of each class period. In addition to pedometer data, your child will take the motivational climate questionnaire and an enjoyment questionnaire the last day of data collection. The PACES questionnaire requests information about your child's enjoyment towards physical education, and the perceived motivation climate questionnaire (PMCSQ-2) requests information about your child's perception of the learning environment. There is a timeline below to help with procedures.

Day 1 - Collect pedometer data from each participant

Day 2 - Collect pedometer data from each participant

Day 3 - Collect pedometer data from each participant

Day 4 - Collect pedometer data from each participant

Day 5 - Administer the PMCSQ-2 and PACES questionnaire prior to the start of class.

WHAT ARE THE POSSIBLE RISKS AND DISCOMFORTS?

To the best of our knowledge, the things your child will be doing will have no more risk of harm than you would experience in everyday life.

\section{WILL YOUR CHILD BENEFIT FROM TAKING PART IN THIS STUDY?}

There is no guarantee that your child will get any benefit from taking part in this study. However, some children may become more aware of their views towards physical education. Your child's willingness to take part, however, may, in the future, help society as a whole better understand this research topic.

\section{DOES YOU CHILD HAVE TO TAKE PART IN THE STUDY?}

If your child decides to take part in the study, it should be because you really want to volunteer. Your child will not lose any benefits or rights they would normally have if they choose not to volunteer. Your child can stop at any time during the study and still keep the benefits and rights they had before volunteering. Your child's academic status or grade will have no effect on your academic status or grade in the class if they decide not to take part in this study.

\section{IF YOUR CHILD DOESN'T WANT TO TAKE PART IN THE STUDY, ARE THERE OTHER CHOICES?}

If your child does not want to be in the study, there are no other choices except not to take part in the study. Your child will continue with the regularly scheduled physical education class, and none of his/her information will be collected. Their physical education grade will not be affected in any way if they do not participate in the research.

\section{WHAT WILL IT COST YOUR CHILD TO PARTICIPATE?}

There are no costs associated with taking part in the study.

WILL YOUR CHILD RECEIVE ANY REWARDS FOR TAKING PART IN THIS STUDY?

Your child will not receive any rewards or payment for taking part in the study.

WHO WILL SEE THE INFORMATION THAT YOU GIVE? 
We will make every effort to keep confidential all research records that identify you to the extent allowed by law.

Your child's information will be combined with information from other people taking part in the study. When we write about the study to share it with other researchers, we will write about the combined information we have gathered. Your child will not be personally identified in these written materials. We may publish the results of this study; however, we will keep your child's name and other identifying information private.

We will make every effort to prevent anyone who is not on the research team from knowing that your child gave us information, or what that information is. For example, your child's name will be kept separate from the information you give, and these two things will be stored in different places under lock and key.

We will keep private all research records that identify your child to the extent allowed by law. However, there are some circumstances in which we may have to show your child's information to other people. For example, the law may require us to show your information to a court. Also, we may be required to show information which identifies your child to people who need to be sure we have done the research correctly; these would be people from such organizations as the University of Kentucky.

\section{CAN YOUR CHILD'S TAKING PART IN THE STUDY END EARLY?}

If your child decides to take part in the study, they still have the right to decide at any time that you no longer want to continue. Your child will not be treated differently if you decide to stop taking part in the study.

\section{WHAT ELSE DO YOU NEED TO KNOW?}

There is a possibility that the data collected from your child may be shared with other investigators in the future. If that is the case, the data will not contain information that can identify your child unless you give your consent or the UK Institutional Review Board (IRB) approves the research. The IRB is a committee that reviews ethical issues, according to federal, state and local regulations on research with human subjects, to make sure the study complies with these before approval of a research study is issued.

\section{WHAT IF YOU HAVE QUESTIONS, SUGGESTIONS, CONCERNS, OR COMPLAINTS?}

Before you decide whether to accept this invitation to take part in the study, please ask any questions that might come to mind now. Later, if your child has questions, suggestions, concerns, or complaints about the study, you can contact the investigator, Christine Johnson, at 678-469-2602 or by email at cejohnson46@gmail.com. If you or your child has any questions about their rights as a volunteer in this research, contact the staff in the Office of Research Integrity at the University of Kentucky between the business hours of 8 am and $5 \mathrm{pm}$ EST, Mon-Fri. at 859-257-9428 or toll free at 1-866-400-9428. Please keep one copy of this consent form for your records.

Signature of person agreeing to take part in the study

Printed name of person agreeing to take part in the study 
Appendix D

Student Assent Form 


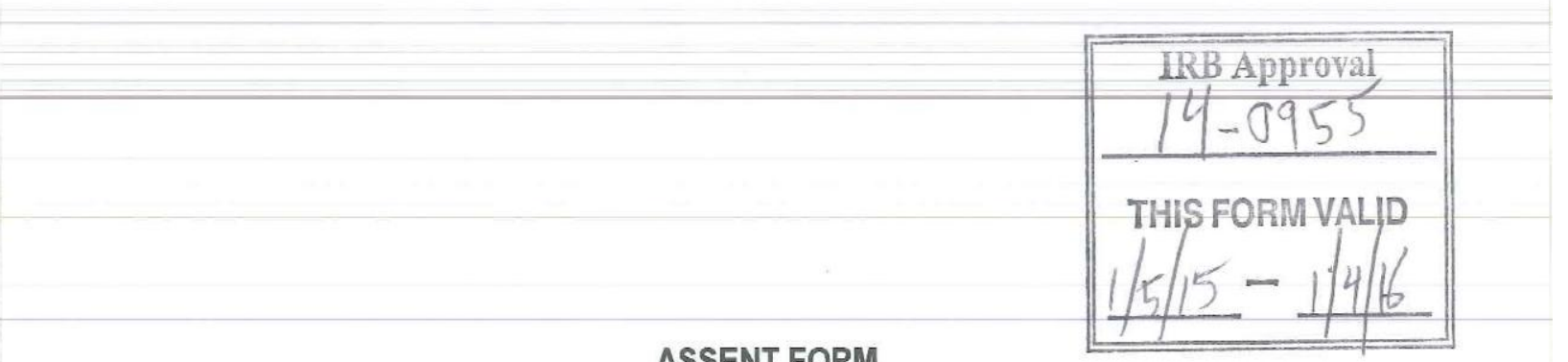

\section{ASSENT FORM}

\section{Student Perceived Motivational Climate, Student Enjoyment, and Physical Activity in Middle School Physical Education}

You are invited to be in a research study being done by Christine Johnson from the University of Kentucky. You are invited because you attend one of three middle schools in Fayette County: Tates Creek Middle, Leestown Middle, or Bryan Station Middle.

If you agree to be in the study, you will be asked to do two things: (1) wear a pedometer on your waistband for four consecutive lessons in physical education, and (2) complete one handout on your motivation and enjoyment in physical education.

During four physical education classes you will wear a pedometer on your waistband. The pedometer records your step counts and activity time. I will record this information at the end of each class period. In addition to pedometer collection, you will take the motivational climate questionnaire and an enjoyment questionnaire the last day of data collection. The questionnaire requests information about your enjoyment towards physical education, and information about your perception of the learning environment.

For participating in this study, you will not receive any sort of prize.

Your family will know that you are in the study. If anyone else is given information about you, they will not know your name. A number or initials will be used instead of your name.

If something makes you feel bad while you are in the study, please tell Christine Johnson. If you decide at any time you do not want to finish the study, you may stop whenever you want.

You can ask Christine Johnson questions any time about anything in this study. You can also ask your parent any questions you might have about this study.

Signing this paper means that you have read this or had it read to you, and that you want to be in the study. If you do not want to be in the study, do not sign the paper. Being in the study is up to you, and no one will be mad if you do not sign this paper or even if you change your mind later. You agree that you have been told about this study and why it is being done and what to do. 


\section{References}

Ames, C. (1992). Classroom goals, structures, and student motivation. Journal of Educational Psychology, 84, 261-271.

Ames, C., Archer, J. (1988). Achievement goals in the classroom climate: student learning strategies and motivation processes. 80, 260-267.

Bandura, A. (1997). Self-efficacy: The exercise of control. New York: Freeman.

Barr-Anderson, D., Neumark-Sztainer, D., Schmitz, K., Ward, D., Conway, T., et al. (2008). But I like PE: factors associated with enjoyment of physical education class in middle school girls. Research Quarterly for Exercise and Sport, 79(1), 18-27.

Bevans, K., Fitzpatrick, L., Sanchez, B., \& Forest, C. B. (2010) Individual and instructional determinant of student engagement in physical education. Journal of Teaching in Physical Education, 29, 399-416.

Beets, M.W., Patton, M.M., \& Edwards, S. (2005).The accuracy of pedometer steps and time during walking in children. Medicine and Science in Sports and Exercise, $37(3), 513-520$.

Beighle, A., Beets, M., Erwin, H., Huberty, J., Moore, J., \& Stellino, M. (2010). Promoting physical activity in afterschool programs. Afterschool Matters, 11, 2432.

Booth, M. \& Okely, A. (2005). Promoting physical activity among children and adolescents: The strengths and limitations of school-based approaches. Health Promotion Journal of Australia, 16(1), 52-54. 
Bowler, M. (2009). The influence of the target motivational climate structures on pupil physical activity levels during year 9 athletics lesson. British Educational Research Association, $\quad$ 1-21.

Brown, L., \& Grineski, S. (1992). Competition in physical education: an educational contradiction. Journal of Physical Education, Recreation and Dance, 63(1), 1719.

Carr, S. \& Weigand, D. (2008). Children's goal profiles and perceptions of the motivational climate: interactive associations with self-determined motivation and affective patterns in physical education. Journal of Social, Behavioral, and Health Sciences, 2 (1), 8-32.

Casey, M., Eime, R., Payne, W., \& Harvey, J. (2009) Using a socioecological approach to examine participation in sport and physical activity among rural adolescent girls. Qualitative Health Research, 1, 1-13.

Centers for Disease Control and Prevention. (2010). School-based physical activity, including physical education, and academic performance, 2010. Retrieved August 22, 2014, from http://www.cdc.gov/healthyyouth/health_and_academics/pdf/pa-pe_paper.pdf.

Crocker, P., Bouffard, M., \& Gessaroli, M. (1995). Measuring enjoyment in youth sport setting: A confirmatory factor analysis of the physical activity enjoyment scale. Journal of Sport and Exercise Psychology, 17, 200-205.

Deci, E. L. \& Ryan, R. M. (1985). Intrinsic motivation and self-determination in human behavior. New York: Plenum. 
Duda, J. L. (1996). Maximizing motivation in sport and physical education among children and adolescents: the case for greater task involvement. Quest, 48, 290302.

Duke, J., Huhman, M., \& Heitzler, C. (2003) Physical activity levels among children aged 9-13 years, 2002. Retrieved August 22, 2014, from http://www.cdc.gov/mmwr/preview/mmwrhtml/mm5233a1.htm.

Dumith, S., Gigante, D., Domingues, M., \& Kohl, H. (2011). Physical activity change during adolescence: a systematic review and pooled analysis. International Journal of Epidemiology, 40, 685-698.

Dweck, C. S. (1986) Motivational processes affecting learning. American Psychologist, 41, 1040-1048.

Dweck, C. S. \& Leggett, E. L. (1983). Achievement motivation. Child Psychology, 643691.

Dweck, C. S. \& Leggett, E. L. (1988). A social-cognitive approach to motivation and personality. Psychological Review, 95, 256-273.

Epstein, J. (1989). Family structures and student motivation: A developmental perspective. In C. Ames \& R. Ames (Eds.), Research on motivation in education. Vol. 3 (pp. 259-295). New York: Academic Press.

Erwin, H. E., Abel, M.G., Beighle, A., \& Beets, M. W. (2009). Promoting children's health through physically active math classes: A pilot study. Health Promotion Practice, 12, 244-151. 
Erwin, H. E., Abel, M.G., Beighle, A., \& Noland, M. P. (2012). The contributions of recess to children's school day physical activity. Journal of Physical Activity and Health, 9, 442-448.

Erwin, H., Beighle, A., Carson, R., \& Castelli, D. (2013). Comprehensive school-based physical activity promotion: a review. Quest, 65, 412-428.

Fairclough, S. \& Stratton, G. (2005). Physical activity levels in middle and high school physical education: a review. Pediatric Exercise Science, 17, 217-236.

Farley, T., Meriwether, R., Baker, E., Rice, J., \& Webber, L. (2008), Where do the children play? The influence of playground equipment on physical activity of children in free play. Journal of Physical Activity and Health, 5, 319-331.

Graham, G. (1992). Teaching children physical education: Becoming a master teacher. Champaign, IL: Human Kinetics.

Graham, G., Holt/Hale, S., \& Parker, M. (2007).Understanding your teaching. In Children Moving: A reflective approach to teaching physical education ( $7^{\text {th }}$ Eds.) (pp. 233-248). New York, NY: McGraw-Hill.

Jooyeon, J. (2013). Evidence-based physical education\#1: What strategies can we use to increase students' MVPA in physical education lessons? Journal of Physical Education, Recreation \& Dance, 84 (6), 17.

Le Masurier, G. C. (2004). Walk which way? ACSM Health \& Fitness Journal, 8(1), 7 10.

Le Masurier, G. C., Lee, S., \& Tudor-Locke, C. (2004). Motion sensor accuracy under controlled and free-living conditions. Medicine and Science in Sports and Exercise, 36(5), 905-910. 
Le Masurier, G. C., \& Tudor-Locke, C. (2003). Comparison of pedometer and accelerometer accuracy under controlled conditions. Medicine and Science in Sports and Exercise, 35(5), 867-871.

Leek, D., Carlson, J., Chain, K., Henrichon, A., Rosenberg, D., Patrick, K.,...Sallis, J. (2011). Physical activity during youth sports practices. Archives of Pediatric and Adolescent Medicine 165, 294-299.

Mahar, M., Murphy, S., Rowe, D., Golden, J., Shields, A., \& Raedeke, T. (2006). Effects of a classroom-based program on physical activity and on-task behavior. Medicine and Science in Sports and Exercise, 38, 2086-2094.

McKenzie, T., Catellier, J., Conway, T., et al. (2006). Girls' activity levels and lesson contexts in middle school PE: TAAG baseline. Medicine and Science in Sports and Exercise, 38(7), 1229-1235.

Metzler, M.W. (1989). A review of research on time in sport pedagogy. Journal of Teaching in Physical Education, 8, 87-103.

Mitchell, S.A. (1996). Relationships between perceived learning environment and intrinsic motivation in middle school physical education. Journal of Teaching in Physical Education, 15, 368-383.

Morgan, C., Beighle, A., \& Pangrazi, R. (2007). What are the contributory and compensatory relationships between physical education and physical activity in children? Research Quarterly for Exercise and sport, 78, 407-412.

Motl, R, Dishman, R, Saunders, R, Dowda, M, Felton, G, Pate, R. (2001). Measuring enjoyment of physical activity in adolescent girls. American Journal of Preventive Medicine, 21(2),110-117. 
Nader, P. (2003). Frequency and intensity of activity of third grade children in physical education. Archives of Pediatrics and Adolescent Medicine, 157, 185-190.

National Council of Youth Sport. (2008). Report on trends and participation in organized youth sports: Market research report NCYS Membership Survey - 2008 Edition. Stuart, FL: Author.

Newton, M., Duda, J., \& Yin, Z. (2000). Examination of the psychometric properties of the perceived motivational climate in sport questionnaire- 2 in a sample of female athletes. Journal of Sport Sciences, 18, 275-290.

Nicholls, J. (1989). The competitive ethos and democratic education. Cambridge, MA: Harvard University Press.

Ntoumanis, N. (2001). A self-determination approach to the understanding of motivation in physical education. British Journal of Educational Psychology, 71, 225-242.

Ntoumanis, N. \& Biddle, S. (1999). A review of motivational climate in physical activity. Journal of Sports Sciences, 17, 643-665.

Papaioannou, A. (1995). Motivation and goal perspectives in children's physical education. In S.J.H. Biddle (Ed.), European perspectives on exercise and span psychology (pp. 245-269). Champaign, IL: Human Kinetics.

Papaioannou, A., \& Kouli, O. (1999). The effect of task structure, perceived motivational climate and goal orientations on students' intrinsic motivation and anxiety. Journal of Applied Sport Psychology, 11, 51-71.

Parish, L. \& Treasure, D. (2003). Physical activity and situational motivation in physical education: Influence of the motivational climate and perceived ability. Research Quarterly for Exercise and Sport, 74 (2), 173-182. 
Ridgers, N., Stratton, G., Fairclough, S., \& Twisk, J. (2007). Long-term effects of a playground markings and physical structures on children's recess physical activity levels. Preventative Medicine, 44, 393-397.

Roberts, G. C. (1992). Motivation in sport and exercise: conceptual constraints and convergence. In G. C. Roberts(Ed.), Motivation in sport and exercise (pp. 199215). Champaign, IL: Human Kinetics.

Ronspies, S. M. (2011). Middle school students' perceptions of coeducational and samesex physical education. Faculty Research and Creative Activity. Paper 2.

Rowe, D., Mahar, M., Raedeke, T., \& Lore, J. (2004). Measuring physical activity in children with pedometers: reliability, reactivity, and replacement of missing data. Pediatric Exercise Science, 16, 343-354.

Sallis, J.F. (2000). Age-related decline in physical activity: a synthesis of human and animal studies. Medicine and Science in Sports and Exercise 32, 1598-1600.

Sallis, J. \& Owen, N. (1999). Physical activity and behavioral medicine. Thousands Oaks, California: Sage.

Sheng, H. \& Gao, Z. (2012). Ethnicity differences in pedometer-based physical activity levels among adolescent girls. Journal of Exercise Science \& Fitness, 10(1), 3843.

Sibley, B. A., \& Etnier, J. L. (2003). The relationship between physical activity and cognition in children: A meta-analysis. Pediatric Exercise Science, 15(3), 243256.

Society of Health and Physical Educators. (2013). Guide for effective physical education policy. Retrieved October 7, 2014, from 
http://www.shapeamerica.org/advocacy/upload/Guide-for-Effective-PE-Policy-722-14.pdf.

Treanor, L., Graber, K., Housner, L., \& Wiegnad, R. (1998). Middle school students' perceptions of coeducational and same-sex physical education classes. Journal of Teaching in Physical Education, 18(1), 43-56.

Troiano, R., Berrigan, D., Dodd, K., Masse, L., Tilert, T., \& Mcdowell, M. (2007). Physical activity in the united states measured by accelerometer. Medicine and Science in Sports and Exercise, 40(1), 181-188.

Trost, S. G., Rosenkranz, R. R., \& Dzewaltowski, D. (2008). Physical activity levels among children attending after-school programs. Medicine and Science in Sports and Exercise, 40(4), 622-629.

Tudor-Locke, C., Lee, S. M., Morgan, C. F., Beighle, A., \& Pangrazi, R. P. (2006). Children's pedometer determined physical activity patterns during the segmented school day. Medicine and Science in Sports and Exercise, 38, 1732-1738.

Ulrich, T., \& Swalm, R. (2007). A pilot study of a possible effect from a motor task on reading performance. Perceptual and Motor Skills, 101, 1035-1041.

United State Department of Health and Human Services. (2010). Strategies to improve the quality of physical education. Retrieved October 7, 2014, from http://www.cdc.gov/healthyyouth/physicalactivity/pdf/quality_pe.pdf.

United States Department of Transportation, Federal Highway Administration Office. (2009). Increasing physical activity. Retrieved August 22, 2014, from http://www.letsmove.gov/sites/letsmove.gov/files/TFCO_Increasing_Physical_Activity.p df. 
Vazou.S., Ntoumanis, N., \& Duda, J. (2005). Peer motivational climate in youth sport: A qualitative inquiry. Psychology of Sport and Exercise, 6(5), 497-516.

Vincent S.D., \& Pangrazi R.P. (2002). Reactivity in children when using pedometers. Pediatric Exercise Science, 14, 432-441.

Wechler, H., McKenna, M. L., Lee, S. M., \& Diets, W. H. (2004). Role of schools in preventing childhood obesity. The State Education Standard, 5(2), 4-12.

Welk, G. (2002). Physical activity assessment in health related research. Champaign, IL: Human Kinetics.

Weiss, M.R., Corbin, C.B. \& Pangrazi, R. P. (2000). Motivation Kids in Physical Activity. President's Council on Physical Fitness and Sport Research Digest. 3(11), 1-8.

White, S. A., Kavassanu, M., \& Guest, S. (1998). Goal orientations and perceptions of the motivational climate created by significant others. European Journal of Physical Education, 3, 212-228.

Whitt-Glover, M.C., Taylor, W.C., Floyd, M.F., Yore, M.M., Yancey, A.K. \& Matthews C.E. (2009). Disparities in physical activity and sedentary behaviors among US children and adolescents: prevalence, correlates, and intervention implications. Journal of Public Health Policy, 30, 309-334.

Wickel, E. E., Eisenmann, J. C., Pangrazi, R. P., Graser, S. V., Raustorp, A., Tomson, L. M. \& Cuddihy, T. F. (2007). Do children take the same number of steps every day?. American Journal of Human Biology, 19, 537-543. 
Youth risk behavior surveillance—United States, 2005. MMWR Surveill Summ 2006;

55, 1-108. Retrieved May 15, 2015 from

http://www.cdc.gov/mmwr/preview/mmwrhtml/ss5505a1.htm\#tab52 


\section{Curriculum Vita}

EDUCATION Georgia Southern University, Statesboro, GA

Masters of Science in Kinesiology, May 2011

Georgia Southern University, Statesboro, GA

Bachelor of Science in Education: Health and Physical Education May 2010

\section{TEACHING}

August 2015- Present University of West Georgia, Carrollton, GA

Instructor of Health and Physical Education

Department of Leadership and Instruction

\section{Publications}

Erwin, H. E., Babkes Stellino, M., Beets, M. W., Beighle, A., \& Johnson, C. E. (2013). Physical education lesson content and teacher style and elementary students' motivation and physical activity levels. Journal of Teaching in Physical Education.

Johnson, C. E., Moore, E., \& Thornton, M. (2014). A smart approach to motivating students in secondary physical education. Journal of Physical Education, Recreation \& Dance.

Moore, E., Johnson, C., \& Thornton, M. (2013). Planning effective outdoor lessons for physical education. Journal of Physical Education, Recreation \& Dance, 84(5), 11-13.

\section{Presentations}

\section{National}

Johnson, C. (2016) Student perceived motivational climate, enjoyment, and physical activity levels in middle school physical education.

Thornton, M., Moore, E., Johnson, C., Erwin, H., \& Stellino, M. (2014). Relationship between recess and physical activity levels and the built environment.

Erwin, H. E., Beighle, A., Johnson, C., Moore, E., Thornton, M., \& Benton, D. (2013). Impact of professional development on student activity during physical education. Research Quarterly for Exercise and Sport.

Pritchard, T., Johnson, C., \& McCollum, S. (2013). Analysis of sport education model on university weight training courses.

\section{State}

Johnson, C., Larson, J., \& Loomis, S. (2015) Using TARGET Structures in Physical Education. GAHPERD

McCollum, S., Johnson, C., \& Peeples, S. (2015) Strategies for Increasing Physical Activity Levels while Teaching Sports Skills. GAHPERD

Knoll, C. \& Johnson, C. (2015) Getting Outside the Classroom in Higher Education. GAHPERD

Moore, E., Johnson, C., \& Thornton, M. (2014). P.R.A.I.S.E. -- Strategies to Promote Motivation in Youth Sports. KAHPERD 
Erwin, H. E., Johnson, C., Moore, E., \& Thornton, M. (2013). Physical Activity in Adapted Physical Education. KAHPERD

Erwin, H. E., Johnson, C., Moore, E., \& Thornton, M. (2013). Teaching Fitness Activities K-12. KAHPERD

McCollum, S., Pritchard, T., Johnson, C., Kendrick, A., Fisher, J., \& Harrelson, S. (2011).

Increasing MVPA in physical education classes. GAHPERD

Professional Clinton County School District, August 2014

Development

Vice President Health Elect, October 2015-Present

Relevant Pearson edTPA Scorer, Carrollton, GA December 2015- Present

Experience Scorer for Physical Education edTPA Portfolios

University of Kentucky, Lexington, KY August 2012- Present

Instructor, Department of Kinesiology and Health Promotion

Kentucky Teacher Internship Program (KTIP), August 2013-December 2013

BalanceME Camp, Santa Cruz, CA June-August 2012

Program Director

STEM School and Academy, Highlands Ranch, CO Aug 2011- May 2012

Health and Physical Education Teacher

New Image Camp Vanguard, Haines City, Florida June 2011- Aug 2011

Athletic Director May 2010

Georgia Southern University, Statesboro, GA May 2010- June 2010/Aug 2010 -

Graduate Assistant, Department of Health and Kinesiology May 2010

Statesboro Bulloch County Parks and Recreation Dep. Statesboro, GA Jan 2009-

PE Activity Coordinator

\section{Professional Membership}

Member of the Society of Health and Physical Educators (2012-Present)

Member of the Georgia Association for Health, Physical Education, Recreation and Dance(2015)

Member of the Kentucky Association for Health, Physical Education, Recreation and Dance

(2012-2015) 